\title{
0 imigrante segundo as Ciências Sociais brasileiras, 1940-1960
}

\section{Gustavo T. Taniguti*}

\section{Resumo}

Neste texto, examino os estudos sobre imigrantes no Brasil produzidos nas ciências sociais brasileiras entre as décadas de 1940 e 1960. Exploro a dinâmica de relações que contribuiu para a realização desses estudos, considerando as atividades de certos intelectuais que tiveram centralidade naquele contexto, a formação de redes internacionais de pesquisadores e os conteúdos teórico-metodológicos que ali foram produzidos e mobilizados. Argumento que dois movimentos situados no pós-guerra exerceram grande impacto nos quadros de análise da questão migratória nas ciências sociais brasileiras: a internacionalização do debate acadêmico-científico e as disputas entre diferentes projetos acadêmicos. Especificamente, são consideradas tanto a participação brasileira em iniciativas de estudos sobre imigração patrocinadas pela Organização das Nações Unidas para a Educação, Ciência e Cultura (UNESCO), quanto as críticas dirigidas aos estudos de comunidades produzidas nas ciências sociais paulistas. Esses dois movimentos impactaram diretamente nos esquemas analíticos propugnados por cientistas sociais, ao redefinirem a condição do imigrante e estimularem o estabelecimento de novos parâmetros para o estudo das relações étnico-raciais. O artigo pretende ampliar o entendimento atualmente disponível sobre a constituição desse eixo temático de estudos, historicamente voltado à discussão de temas candentes à sociedade brasileira, como o preconceito, o racismo, a segregação, a inclusão social, a democracia e a identidade nacional.

Palavras-chave: História das ciências sociais, Estudos migratórios, Imigração, UNESCO, Assimilação.

* Universidade de São Paulo, São Paulo, SP, Brasil. 


\section{The immigrant in Brazilian social sciences, 1940-1960}

\section{Abstract}

In this article, I examine the studies on immigrants in Brazil, produced in the Brazilian social sciences between the 1940s and 1960s. I explore the dynamics of relationships that contributed to the production of these studies, considering the activities of some intellectuals that had a central role in that context, the formation of international networks of researchers and the theoretical-methodological content produced and mobilized there. It is argued that two post-war movements had a great impact on the analysis of the migratory issue in the Brazilian social sciences: the internationalization of the academic-scientific debate and the disputes between different academic projects. In particular, both the Brazilian participation in immigration studies initiatives sponsored by the United Nations Educational, Scientific and Cultural Organization (UNESCO) and the criticisms directed at the studies of communities produced in the social sciences of São Paulo are considered here. These two movements have directly impacted on the analytical frameworks advocated by social scientists, by redefining the condition of the immigrant and encouraging the establishment of new parameters for the study of ethnic-racial relations. The article intends to broaden the understanding currently available on the constitution of this field of studies historically focused on the discussion of themes so controversial in Brazilian society, such as prejudice, racism, segregation, social inclusion, democracy and national identity.

Keywords: History of social sciences, Migration studies, Immigration, UNESCO, Assimilation

\section{Introdução}

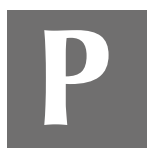

oucos anos após a fundação das primeiras instituições dedicadas ao ensino e à pesquisa na área das ciências sociais no Brasil, teve início um significativo processo de estabelecimento profissional das disciplinas sociológica e antropológica. Isso foi acompanhado de iniciativas voltadas à organização disciplinar especializada, o que demandou, entre outros aspectos, a definição de temas de pesquisa e o estabelecimento de quadros teórico-metodológicos. Os estudos sobre imigrantes produzidos pelas ciências sociais brasileiras tiveram início nesse contexto, em fins dos anos trinta, justamente quando a presença de imigrantes em diversas regiões 
do país era evidente e, em contraposição, a entrada de estrangeiros passava a sofrer progressivas restrições por meio da política governamental. Mais ainda, a aceitação social de vários grupos imigrados pela população nativa era uma realidade por vezes distante.

Nas décadas seguintes, o tema da imigração e os fenômenos a ele associados estiveram presentes nas obras de inúmeros intelectuais pertencentes a diversas áreas - história, geografia, sociologia, antropologia, demografia, psicologia -, tendo alcançado certa posição destacada no conjunto da produção acadêmica nacional. A despeito disso, os estudos sobre imigrantes ainda aguardam exames apurados que possibilitem melhor inscrevê-los na história das ciências sociais brasileiras. Este trabalho busca ampliar o entendimento atualmente disponível a seu respeito e, para isso, avalia obras, autores e instituições envolvidos na condução de pesquisas sobre o tema entre as décadas de 1940 e 1960. Maior ênfase é conferida a processos de composição e mudança de quadros teóricos de análise, condições indispensáveis para o estabelecimento de regimes de cientificidade, visto que principalmente as disciplinas da sociologia e da antropologia contribuíram para desmobilizar muitas interpretações conservadoras - geralmente de caráter ensaístico e amador - tão presentes nos debates sobre imigração desde o início do regime republicano ${ }^{1}$. Examinar tais processos demanda bem situar os conteúdos dos estudos sobre imigrantes no espaço e no eixo temporal.

Argumento aqui que tanto as disputas travadas no campo científico paulista envolvendo diferentes projetos acadêmicos quanto a internacionalização de pesquisadores e instituições exerceram grande impacto nos quadros de análise voltados à investigação do imigrante nas ciências sociais brasileiras. Considero, especificamente, as críticas ao modelo cultural-assimilacionista proposto pelo antropólogo e sociólogo alemão Emílio Willems e a participação brasileira em iniciativas de estudos sobre imigração patrocinadas pela Organização das Nações Unidas para a Educação, Ciência e Cultura (UNESCO).

Em um primeiro momento, entre os anos trinta e a primeira metade dos anos cinquenta, os estudos sobre imigrantes privilegiaram a investigação

1 Vide as críticas de Emílio Willems em Assimilação e populações marginais no Brasil (1940). 
do contato entre grupos de origens distintas. Foi quando a abordagem cultural-assimilacionista adquiriu proeminência nos meios acadêmicos. Posteriormente, o lugar do estrangeiro na sociedade brasileira passou a ser redefinido nos esquemas analíticos propugnados por cientistas sociais. Neles, a condição do imigrante continuou pressupondo a existência de desigualdades, mas o seu entendimento foi deslocado da estrutura de relações étnico-raciais, que forneceria possibilidades de superação mediante a adoção de padrões culturais (assimilação), para se aproximar cada vez mais de uma estrutura de relações mercantis, que forneceria possibilidades de superação mediante a mobilidade socioeconômica e a inserção em melhores posições na estrutura ocupacional (integração).

É bem provável que a mobilidade ascensional experimentada por parte considerável dos imigrantes e seus descendentes contribuiu para que se afirmasse, sob o léxico da democracia racial, um discurso sobre a capacidade inclusiva e não discriminatória da nação brasileira. Mas no caso da população não branca, a sua inserção na estrutura de classes não ocorreu alheia a outros sistemas classificatórios e, isoladamente, não anulou os efeitos da racialização ${ }^{2}$. Independentemente da validade das proposições contidas nesses esquemas analíticos, o saber científico produzido pelos estudos sobre imigrantes esteve em sintonia com uma orientação do pós-guerra que priorizou, sobretudo, confrontar desigualdades mediante a evitação e a redução de conflitos entre grupos. Propalado no imaginário coletivo e asseverado pelo conhecimento científico, o ideário integracionista ganhou espaço na produção acadêmica e foi disseminado alhures, relegando a um plano secundário a questão do preconceito contra grupos estrangeiros, a despeito da persistência dos estereótipos raciais que caracterizam tão fortemente as formas assimétricas de organização coletiva em nossa sociedade.

Diversamente de como foram constituídos os estudos sobre imigrantes em outros países latino-americanos ${ }^{3}$, o caso brasileiro possui características

${ }^{2}$ Sobre esse assunto, ver Guimarães (2002; 2012).

${ }^{3}$ Ver: Brasil Jr. (2010) e Blanco e Jackson (2014). 
cuja compreensão demanda considerar tanto as particularidades constitutivas da sociedade patriarcal quanto a transformação das categorias de classificação étnico-racial. Examinar a trajetória dos estudos sobre imigrantes no período considerado é uma oportunidade adequada para se trazer à discussão, sob um prisma renovado, as articulações existentes entre imigração e raça.

\section{Processo de objetivação e condições de objetividade}

Uma das primeiras publicações que arrolaram a literatura sociológica nacional de orientação estritamente acadêmica produzida até 1940 já assinalava a existência de estudos sobre a presença de estrangeiros no país (Pierson, 1945a). Eles foram concebidos principalmente em São Paulo, em fins dos anos trinta, logo após o estabelecimento de instituições educacionais e de cultura consideradas inovadoras à época, como a Escola Livre de Sociologia e Política (ELSP), a Faculdade de Filosofia, Ciências e Letras (FFCL) e o Departamento de Cultura do Município de São Paulo (dirigido por Mário de Andrade entre 1935 e 1939). A despeito de esses estudos inaugurarem localmente as pesquisas sobre o tema da imigração, eles foram realizados de maneira pontual e não exaustiva, de forma que esteve ausente um programa de investigação dedicado.

Tais estudos foram empreendidos por pesquisadores partícipes da Sociedade de Etnografia e Folclore, associação criada em 1937 no âmbito do Departamento de Cultura, e cujo interesse maior de pesquisa esteve centrado em temas como folclore, padrões e as condições de vida, hábitos, formas de ocupação urbana. A despeito desse enfoque, a crescente presença de estrangeiros em São Paulo tornou pertinente a "colaboração da antropologia na detecção das fronteiras culturais da cidade" (Valentini, 2010, p. 134), e algumas investigações voltadas a estrangeiros foram conduzidas e logo publicadas na Revista do Arquivo Municipal (RAM) ${ }^{4}$. Mais especificamente, esses primeiros estudos buscavam melhor caracterizar a presença de

4 São exemplos disso os artigos de Samuel Lowrie (1937; 1938), Rafael Paula Souza (1937), Cecília Castro e Silva e Maria Stella Guimarães (1937) e Sérgio Milliet (1938). 
imigrantes na cidade em termos de ocupação urbana, concentração geográfica, criminalidade e composição familiar.

Naqueles anos, ainda de forma tentativa, autores interessados davam início à definição de temas e objetos de pesquisa a serem analisados por excelência pela antropologia e pela sociologia, disciplinas que ao longo do tempo se tornaram linguagem privilegiada para interpretar as transformações em curso na sociedade brasileira. Isso ocorreu processualmente, acompanhando os debates políticos e intelectuais que permearam o desenvolvimento e a gestão das incipientes ciências sociais no país.

Nutridos por aspirações singulares como a definição de valores nacionais e a necessidade quase impositiva de caracterizar a sociedade brasileira, cientistas sociais passaram a delinear os interesses de investigação de seus estudos, bem como propuseram conteúdos programáticos, valeram-se de certos referenciais teóricos, definiram e aplicaram métodos de pesquisa específicos. Esse processo de objetivação contribuiu para o progressivo desenvolvimento de um eixo temático de investigação sobre a imigração que ao longo dos anos se tornou significativo, visto que nas décadas subsequentes projetou pesquisadores, estimulou a produção científica e promoveu a discussão de ideias e a condução de estudos em âmbito nacional e internacional.

No período que se estende até os anos cinquenta, os estudiosos dedicados à temática da imigração nas ciências sociais brasileiras estiveram interessados sobretudo nos processos resultantes do contato entre grupos de origens e características distintas. Mais do que simplesmente colocar à prova o imaginado discurso sobre a capacidade inclusiva e não discriminatória da nação - mesmo que isso implicasse na adoção de pressupostos como a mudança da mentalidade do imigrado e a subordinação de "nacionalismos estranhos" a valores predominantes na sociedade receptora -, os resultados de seus estudos tiveram repercussão no debate público da época, devido à sua capacidade de atestar o relativo sucesso em incorporar imigrantes sob um viés estritamente cultural, relegando o determinismo biológico das visões racistas ao anacronismo. Desse modo, esses cientistas ofereceram alternativas para enfrentar posições de certos grupos sociais que repudiavam 
a presença de estrangeiros no país ou mesmo a retomada da imigração, ocorrida em 1945.

É válido ressaltar que, poucos anos antes, oferecendo suporte às políticas de cerceamento de direitos promovidas pelo governo brasileiro durante o Estado Novo (1937-45), as posições nativistas emergiram com força no debate público, geralmente oferecendo leituras apócrifas do eugenismo europeu. Para alguns representantes da intelligentsia local, a exemplo de médicos e juristas, a imprensa e as comissões constituintes foram os cenários oportunos para a defesa de seus ideais de sociedade estruturada em bases raciais. Não há dúvidas de que havia uma forte resistência local à aceitação de estrangeiros (principalmente os de origem não europeia), embora a sua presença no mercado de trabalho fosse notável em números cada vez maiores. Face à impossibilidade do completo impedimento da presença de imigrantes, o conceito de assimilação foi adotado por entusiastas da campanha de nacionalização e em ensaios considerados sociológicos à época, como Raça e assimilação, de Oliveira Vianna (1932). Influenciados pelas ciências naturais, autores partilhavam das ideias de superioridade racial branca afirmadas à época, e defendiam o cruzamento e a mestiçagem como forma de branqueamento da população - condição para se preservar supostos traços e qualidades humanas por eles desejados.

Dessa forma, o ideário assimilacionista incitou, na prática, a busca quase obsessiva pelo abrasileiramento de imigrantes, e seus resultados foram vistos na formulação da política migratória e na orientação repressiva adotada pelo Estado durante a campanha de nacionalização (Seyferth, 2004). Além de evidenciar um forte conservadorismo, essas medidas indicavam que o estatuto do imigrante havia passado de "solução" para a escassez de mão de obra a um "problema" para a formação da identidade nacional. Qualquer cientista social que lidasse com o tema da imigração naquele contexto era desafiado a equacionar o dilema do imigrante, atribuindo-lhe um lugar no imaginário nacional.

Conceber o imigrante enquanto objeto de investigação e interpretar os fenômenos a ele associados a partir de certos conceitos e corpora teóricos 
dependeram de avaliações individuais de pesquisadores, feitas com base em sistemas de valores e mediadas por estruturas relacionais e institucionais. Refiro-me a condições de objetividade como, por exemplo, a formação universitária, a origem social, as relações profissionais de pesquisa, os contextos de produção acadêmica, as disputas institucionais, os contextos políticos, as experiências de vida, os interesses e preferências individuais. Sublinho, portanto, que fatores de natureza política e cultural não incidem somente sobre os objetos de estudo e de reflexão sociológica, mas também sobre aqueles que empreendem a análise (Mauger, 1999). Sob esse entendimento, não é surpreendente que cientistas sociais de origem estrangeira cujas carreiras profissionais foram construídas no Brasil - a exemplo de Emílio Willems e Hiroshi Saito - fossem os mais interessados em investigar a vida dos imigrados.

Neste artigo, o exercício de identificar certos mecanismos e dinâmicas que operam a construção do conhecimento científico representa um ponto de partida para o objetivo aqui proposto de investigar o desenvolvimento dos estudos sobre imigrantes e desnudar sua participação na formação das ciências sociais brasileiras em um período inicial. Um segundo ponto a ser destacado está associado ao anterior e resulta de uma avaliação sobre as pesquisas atuais, em que duas críticas merecem ser explicitadas. Por um lado, a forma como no Brasil atualmente autores têm realizado revisões bibliográficas dos estudos sobre imigrantes privilegia o conteúdo das obras em detrimento do meio social dinâmico que envolve a sua produção, o que tem resultado em avaliações de alcance restrito. E, por outro, a história da formação disciplinar da sociologia em São Paulo ainda aguarda exames dedicados ao tema da imigração que melhor situem o debate sobre relações étnico-raciais e considerem o valor de projetos acadêmicos praticamente omitidos das narrativas existentes.

\section{Estudos sobre imigrantes no Brasil: composição e mudança do modelo cultural-assimilacionista}

Na literatura especializada é consenso que o livro Assimilação e populações marginais no Brasil, de autoria do antropólogo e sociólogo 
alemão Emílio Willems (1940), inaugurou uma proposta de investigação sistemática de fenômenos presentes na vida de imigrantes no âmbito das ciências sociais brasileiras. Para isso, o autor propôs um modelo centrado na análise de processos de mudança sociocultural a partir do contato interétnico. Este último passou a ser traduzido em conceitos como "assimilacão", "aculturação", "marginalidade", em grande medida baseando-se em formulações teóricas de autores da Universidade de Chicago, instituição amplamente conhecida na época por ter comportado o primeiro departamento de sociologia dos Estados Unidos e realizado pesquisas sobre imigração, cidade, trabalho, exclusão e relações raciais.

Emílio Willems foi docente da ELSP e FFCL entre 1937 e 1949. Nesta última, foi o primeiro professor a assumir a cadeira de Antropologia I, em 1941. Sob forte influência inicial do sociólogo estadunidense Donald Pierson (docente da ELSP entre 1939 e 1959), produziu uma obra extensa e diversificada, assim como teve participação ativa na institucionalização das ciências sociais em São Paulo ${ }^{6}$ : foi membro-fundador e primeiro-secretário da Sociedade de Sociologia de São Paulo, criada em 1937, membro-fundador da já mencionada Sociedade de Etnologia e Folclore, fundador da revista Sociologia, criada em 1939, além de organizar a publicação de dicionários acadêmicos e atuar como tradutor de autores alemães.

Revisionistas afirmam que a despeito de Willems ter deixado o país definitivamente no ano de 1949, o modelo voltado à análise cultural dos imigrantes por ele proposto subsistiu como parte do legado das primeiras iniciativas dedicadas ao desenvolvimento de ferramentas teórico-conceituais de pesquisa nas ciências sociais brasileiras. Imprimindo certa marca autoral, Willems buscou traduzir fenômenos que observou em colônias alemãs no sul do Brasil, tendo como referência teórica a literatura estadunidense que Ihe foi apresentada por Donald Pierson. Nela figuravam obras de antigos colegas com quem Pierson conviveu no Seminário Pós-Graduado Dedicado ao Estudo dos Contatos Racial e Cultural, criado em 1931 na Universidade

${ }^{5}$ Para mais detalhes sobre o tema da assimilação, ver Truzzi (2012).

${ }^{6}$ A sua obra publicada no Brasil é extensa e abordou diversos temas situados na interface da antropologia e da sociologia. Para mais detalhes, ver Villas-Bôas (2000). 
de Chicago e coordenado por Robert Park, Robert Redfield, Herbert Blumer, Louis Wirth, Radcliffe-Brown, Lloyd Warner e Everett Hughes (Pierson, 1945a). Desde os anos trinta, esses autores haviam engendrado um debate sobre as formas de contato cultural que teve grande repercussão no meio acadêmico norte-americano. Comumente denominado "aculturação" ou "assimilação", esse debate se tornou central para estudiosos de diversos temas na sociologia e na antropologia brasileiras, tais como religião, imigração, comunidades rurais, etnologia, educação (Faria, 1993, p. 253).

Ainda segundo as interpretações vigentes, na década subsequente, a produção sobre o tema dos imigrantes teria se caracterizado por um progressivo distanciamento do modelo cultural-assimilacionista, para progressivamente se aproximar de uma abordagem interessada no pluralismo e na valorização das particularidades culturais de cada grupo (Seyferth, 2004). Basicamente, o quadro analítico inaugurado por Willems teria sido suplantado por outras abordagens derivadas, em que a noção de "assimilação" estaria "ancorada a noções mais dinâmicas de mobilidade social e de mudanças na sociedade" (Truzzi, 2012, p. 527) e, portanto, mais distante da perspectiva adotada nos "estudos de comunidades" tradicionais.

Em decorrência disso, o termo "integração" teria sido mais amplamente disseminado e utilizado no Brasil por conceber o comportamento cultural inserido em estruturas sociais mais amplas. Essa abordagem teria coexistido com aquelas tributárias do modelo cultural-assimilacionista, ao menos até os anos oitenta, quando este último encontrou o seu esgotamento, tanto no debate acadêmico nacional quanto no internacional. A diferença latente entre os dois tipos de abordagens é que a perspectiva integracionista teria possibilitado, no plano discursivo, uma associação mais direta entre as noções de integração e de mobilidade ascensional. Nessa perspectiva, os estudos migratórios sob o viés assimilacionista teriam entrado em declínio, devido ao surgimento de outras abordagens consideradas mais aptas para apreender a complexidade das formas de integração e de manifestação das diferenças culturais.

Ainda que procedente, essa avaliação encontra limites, por interpretar o surgimento e a mudança de quadros de análise unicamente a partir dos 
conteúdos presentes em obras selecionadas. De maneira distinta, acredito que essa tarefa demanda dos pesquisadores uma percepção ampliada sobre a produção de conhecimento, em que autores e obras são avaliados enquanto produtos que só adquirem sentido em congruência com relações sociais e com o momento histórico em que se inserem.

Pesquisas atuais voltadas à história das ciências sociais brasileiras oferecem contribuições proveitosas a esse respeito. Elas frequentemente têm estimulado um debate sobre os significados contidos na atividade sociológica e antropológica profissional, e buscado, assim, identificar aspectos centrais de sua constituição. São tópicos expressivos desse debate as atividades que tiveram lugar nas instituições pioneiras de pesquisa e ensino e o estabelecimento de temas de investigação. Especificamente, essa literatura complementa a compreensão dos movimentos de emergência e perecimento da abordagem cultural-assimilacionista, ao evidenciar a existência de diferentes projetos acadêmicos no âmbito da sociologia paulista e as disputas que eles suscitaram (Jackson, 2009), muito embora ela ainda não ofereça uma apreciação pormenorizada dos estudos sobre imigrantes. Outras contribuições advêm de propostas para a análise da circulação de conhecimento científico envolvendo agências e instituições transnacionais ou intergovernamentais. Elas buscam traduzir os impactos e os desdobramentos para o campo acadêmico advindos de movimentos de importação, transferência, tradução e transformação de ideias (Christensen; Ydesen, 2015).

\section{Estudos sobre imigrantes e "estudos de comunidades" em convergência}

As primeiras iniciativas de investigação sistemática de imigrantes nas ciências sociais brasileiras, conduzidas por Emílio Willems, abrigam informações ainda pouco exploradas que permitem compreender o estabelecimento e a superação do modelo de apreensão da realidade proposto pelo intelectual alemão. Um aspecto central a ser destacado é que tais iniciativas ocorreram em convergência com uma proposta acadêmica de "estudos de comunidades", assumindo estreito diálogo com a sociologia 
e a antropologia social estadunidenses da época. Desde a Segunda Guerra, essas disciplinas tiveram que adequar as condições de seu desenvolvimento a interesses governamentais estratégicos que visavam a ampliação de sua área de influência científica em países da América Latina. Essa convergência é um dado importante a ser considerado, tendo em vista que as posteriores críticas dirigidas aos "estudos de comunidades" demarcaram um novo período de produção teórico-metodológica nas ciências sociais brasileiras, bem como reverberaram no modelo de análise do contato cultural de viés assimilacionista, amplamente utilizado nos estudos sobre imigrantes.

Interessados em estabelecer um regime de cientificidade e profissionalismo para a sociologia e a antropologia - característica comum às "missões" estrangeiras de docentes trazidas a São Paulo -, Donald Pierson e Emílio Willems estiveram em constante contato com as tendências disciplinares, principalmente as estadunidenses, e procuraram disseminá-las tanto de forma didática quanto aplicada. Portanto, ambos reuniram esforços para criar canais de transmissão de métodos e conteúdo entre o Brasil e outros países, principalmente os Estados Unidos - mesmo que em tal relação residisse o pressuposto da hegemonia cultural e científica destes últimos.

Inicialmente, nos anos trinta, quando Pierson esteve no Brasil para realizar a sua pesquisa de doutorado sobre relações raciais na Bahia, a abordagem ecológica desenvolvida por cientistas sociais de Chicago (como no caso de seu supervisor Robert Park) vivia o seu auge. Na década seguinte, outras propostas passaram a se destacar no meio acadêmico norteamericano, como as que buscavam equacionar o objetivo de generalização da sociologia e a ênfase empírica e descritiva da antropologia, ou mesmo as abordagens comportamentais e de atitudes (Wilcox, 2006).

Pierson afirmava possuir reservas quanto ao ecletismo no método científico, dando preferência ao diálogo da sociologia com a antropologia social (Pierson, 1948). Assim, em meados dos anos quarenta, abandonou certa predileção que anteriormente conferira à abordagem da ecologia humana e se aproximou de temas antropológicos como o da mudança cultural, bem como passou a realizar pesquisas aprofundadas em comunidades rurais. 
Essa nova orientação refletia, em certa medida, as linhas de pesquisas que foram privilegiadas após o estabelecimento do escritório do Institute of Social Anthropology da Smithsonian Institution na ELSP, em São Paulo, entre 1945-52, que teve Pierson como secretário. O propósito do instituto era implementar treinamentos em ensino antropológico e pesquisa em outras repúblicas americanas no contexto do pan-americanismo (Castro, 2010; Faulhaber, 2011). O convênio com a instituição (ligada ao Interdepartmental Committee on Scientific and Cultural Cooperation, do Departamento de Estado do governo estadunidense) deu início a um conjunto de iniciativas locais que impulsionaram o desenvolvimento da antropologia social no imediato pós-guerra, a exemplo da criação do programa de estudos de Pós-graduação em Antropologia na ELSP e da disponibilização de recursos para traduções e publicações, como a Coleção de Ciências Sociais, dirigida por Pierson.

Willems, por sua vez, transitava entre as áreas da sociologia, etnologia e antropologia, bem como estabeleceu um diálogo com a psicologia social ao se interessar na mudança de atitudes dos imigrados e nos efeitos individuais da experiência migratória. Ele era, à época, o cientista social que mais se dedicava ao tema da imigração, e havia adotado uma posição crítica em relação à política estadonovista, expondo as suas opiniões em periódicos como a Revista de Imigração e Colonização e O Estado de S. Paulo. Para além dos outros temas aos quais se dedicou durante os anos em que viveu no Brasil, o seu contato com a literatura antropológica estadunidense ganhou expressão maior em seus trabalhos sobre imigrantes. Em depoimento afirmou: "Prosseguindo os meus estudos de mudança cultural, aprofundeime na literatura sobre aculturação que se estava desenvolvendo rapidamente nos Estados Unidos". As suas referências principais, nesse sentido, foram os antropólogos Robert Redfield e Melville Herskovits, este último que já na década de 1930 era um dos mais importantes discípulos de Franz Boas, sendo internacionalmente conhecido por sua pesquisa sobre os africanismos no Novo Mundo (Guimarães, 2008).

Já Redfield ocupava uma posição de destaque na antropologia estadunidense ao menos desde os anos trinta, quando realizou estudos 
em comunidades rurais e tribos indígenas mexicanas. Mais tarde, em 1944, foi eleito presidente da American Anthropological Association. Ademais, ele possuía boas relações com Pierson, que havia sido seu aluno em Chicago. A partir de 1942 Redfield passou a dirigir o Joint Commitee on Latin American Studies (JCLAS) - instituição que, no contexto das políticas de expansão de influência dos Estados Unidos no continente americano, pretendia formar uma rede de pesquisadores especializados na América Latina. Assim, sob a direção de Redfield, o JCLAS ajudou a estabelecer as diretrizes do Institute of Social Anthropology, que também inaugurou um escritório no México e realizou atividades na Guatemala, Peru e Colômbia. Esses países passaram a ter influência direta da antropologia estadunidense por meio de convênios, projetos de pesquisa, intercâmbio de pesquisadores, criação de periódicos. Um dos legados dessa influência foi a tentativa de aplicar métodos voltados à investigação dos aspectos culturais de comunidades "não primitivas", geralmente localizadas em áreas rurais, e que estariam atravessando significativos processos de mudança.

Apoiados em referências da antropologia norte-americana, e em estreito diálogo com as orientações da Smithsonian Institution, Willems e Pierson se tornaram expoentes, em São Paulo, dos chamados "estudos de comunidades" - estes que, além de estabelecer novos quadros teórico-metodológicos, buscavam fornecer subsídios para políticas públicas governamentais. No Brasil, algumas de suas obras se tornaram emblemáticas dessa proposta, como Cruz das Almas (Pierson, [1951] 1966)7 e Búzios Island (Willems; Mussolini, 1952), sendo que, na literatura, o pioneirismo desses estudos é comumente atribuído ao livro de Emílio Willems (1947) intitulado Cunha tradição e transição em uma cultura rural do Brasil ${ }^{8} \mathrm{e}$, por vezes, às pesquisas de Charles Wagley e Donald Pierson (Wagley, 1955; Goldwasser, 1974; Oliveira; Damaceno, 2009). Foi nesse contexto que Pierson, enfatizando o tema da mudança cultural, procurou apresentar um panorama sobre as pesquisas que poderiam ser conduzidas nas ciências sociais brasileiras, em

${ }^{7}$ Para mais informações, ver Maio et al. (2013).

${ }^{8} \mathrm{O}$ título da obra faz menção ao município de mesmo nome, situado no Vale do Paraíba, estado de São Paulo, onde a pesquisa de campo foi realizada. 
Pesquisa e possibilidades de pesquisa no Brasil - com especial referência à "cultura" e "mudança cultural" (Pierson; Vieira da Cunha, 1947a; 1947b; 1948). A publicação, dividida em três partes, informa que Pierson buscava se apresentar como um dos principais revisores da produção acadêmica nas ciências sociais brasileiras - alguém capaz de indicar as tendências a serem seguidas por pesquisadores e instituições. Nessa publicação, os estudos sobre imigrantes conduzidos por Willems já eram considerados como eixo temático significativo de um campo científico em formação.

Contudo, os que atribuem pioneirismo dos "estudos de comunidade" a Cunha deixam de considerar que trabalhos específicos de Willems já haviam inaugurado essa proposta de investigação ao endossar a perspectiva de intervenção organizada no meio rural, formulada por autores expoentes da sociologia rural estadunidense, como o sociólogo Thomas Lynn Smith (1903-1976). Nos anos trinta e quarenta, Smith estabeleceu contato com Robert Park, Donald Pierson e Arthur Ramos (Guimarães, 2008). Posteriormente, em 1946, foi um dos fundadores do Institute for Brazilian Studies na Universidade de Vanderbilt, em Nashville, Estados Unidos, para onde Willems se transferiu três anos mais tarde.

Assim como Robert Redfield e Julian Steward (antropólogo e diretor do Smithsonian Institution), Thomas Lynn Smith realizou pesquisas para as agências científicas governamentais de seu país no contexto da guerra. Segundo Alexander Lesser (1946), desde 1942 o Departamento de Agricultura dos Estados Unidos havia estabelecido um programa de pesquisas em sociologia rural do qual Smith fez parte. Compartilhando certas orientações de Julian Steward, uma das ideias centrais de Smith era a de fornecer subsídios para políticas dirigidas. Ao realizar estudos no Brasil, o autor vislumbrava, entre outros, a "consolidação de uma classe média de agricultores no Brasil em substituição à rígida e pouco diferenciada estrutura de classes gestada por séculos de latifúndio e escravidão" (Lopes; Maio, 2017, p. 7). Em outras palavras, tratava-se da transformação de "sertanejos e caboclos em farmers e lavradores ativos, membros de uma classe média de fazendeiros" (Lopes; Maio, 2017, p. 7), ou seja, trabalhadores rurais modernos e qualificados. 
Nessa perspectiva, atribuía-se aos imigrantes colonos uma diferença em relação aos sertanejos: os primeiros eram concebidos enquanto agentes de difusão de padrões culturais mais "avançados" pelo fato de dominarem técnicas agrícolas modernas. Willems adotou essa proposta, adequando-a aos estudos sobre imigrantes que até então vinha realizando.

\section{O imigrante: um vetor de mudanças no mundo rural}

Em 1942, além de seu livro Assimilação e populações marginais no Brasil, Willems já havia publicado outros estudos monográficos sobre os alemães no Vale do Itajaí, em Santa Catarina, e sobre os japoneses no Vale do Ribeira, em São Paulo (em parceria com o etnólogo Herbert Baldus), dos quais são exemplos os textos Casas e túmulos japoneses no Vale de Ribeira de Iguape (Baldus; Willems, 1941), Procesos de culturalización lingüística entre poblaciones brasileñas de origen germánico (Willems, 1941a), Recreação e assimilação entre imigrantes alemães e japoneses e seus descendentes (Willems, 1941b) e Cultural change among Japanese immigrants in Brazil (Willems, 1942a). Especificamente os trabalhos sobre os imigrantes japoneses resultaram de incursões experimentais em comunidades com forte presença de imigrantes, realizadas no âmbito dos cursos pós-graduados da Escola Livre de Sociologia e Política, e que contaram com a participação de seus alunos e colegas de profissão como Egon Schaden, Herbert Baldus, Hiroshi Saito e Gioconda Mussolini.

As informações ali obtidas foram utilizadas por Willems na formulação de um quadro de análise das mudanças e dos conflitos culturais no meio rural. Basicamente, ao comparar os japoneses e os alemães, a análise por ele empreendida comportou dois níveis: o coletivo (sistema de valores) e o individual (mentalidade). Sob esse enfoque, foram privilegiados fenômenos como o casamento interétnico, a religião, os hábitos recreativos e o idioma - principalmente devido à sua capacidade de indicar que imigrantes estariam progressivamente adotando os sistemas de valores brasileiros. Outro movimento de interpretação por ele formulado buscou dimensionar as situações particulares vividas pelos imigrantes em um contexto societário 
mais amplo, de forma a discutir os efeitos da modernização, das políticas governamentais agrícolas e das técnicas trazidas por imigrantes à cultura sertaneja tradicional.

Assim, em sintonia com a proposta da sociologia rural estadunidense, Willems afirmou que a imigração era um fator importante a ser analisado no conjunto de mudanças ocorridas no meio rural - algo de magnitude comparável à industrialização. Pois o contato dos estrangeiros com a população nativa teria originado conflitos entre diferentes sistemas de valores, conforme exposto em Some aspects of cultural conflict and acculturation in southern rural Brazil (Willems, 1942b), publicado na revista Rural Sociology:

No Brasil existe um profundo hiato entre os centros urbanos com suas áreas rurais dependentes e aquela parte da população rural que se caracteriza pela autossuficiência econômica e outros traços de uma legítima cultura do folk. Ao lado da industrialização, é principalmente a imigração estrangeira que produz choques culturais (WILLEMS, 1942b, p. 375, grifos meus).

Em linhas gerais, se os "estudos de comunidades" se interessavam pelas mudanças em curso na cultura e na organização social tradicional de pequenos vilarejos, as pesquisas de Willems indicavam que, ao menos em localidades onde a presença estrangeira era significativa, a imigração era um fator a ser considerado. Esse argumento foi aprofundado logo em seguida, nos textos A solução do problema rural brasileiro como mudança cultural provocada (Willems, 1943) e O problema rural brasileiro do ponto de vista antropológico (Willems, [1944] 2009). Este último pode ser entendido como um programa geral dos "estudos de comunidades" no Brasil, em que Willems explicitou seu posicionamento em relação aos problemas que afetavam o meio rural (Jackson, 2009). No texto, o autor assinalou a existência de diferenças, tensões e choques entre as culturas caboclas e a sociedade urbana, no contexto da adoção de iniciativas educacionais. Tendo em vista sua superação, sugeriu um plano de ação científica para a investigação do meio rural, que também deveria contemplar estudos sobre a aculturação de imigrantes e de negros: 
Não se esqueçam dos problemas que a introdução do africano e a imigração de europeus e asiáticos trouxeram. A aculturação desses elementos humanos constitui outro objetivo de estudo, sobretudo de antropólogos e sociólogos. A sua solução científica deverá obedecer a um plano semelhante ao que acima deixei traçado. Também os estudos aculturativos terão de começar por monografias regionais ou locais cujo número há de corresponder exatamente às áreas habitadas por imigrantes ou seus descendentes. Quanto ao negro, essa parte deparará com dificuldades mais sérias (Willems, [1944] 2009, p. 204).

A partir desse formato autoral de realização de "estudos de comunidades", interessado no contato entre as culturas sertaneja e estrangeira, Willems procurou se inserir no debate acadêmico internacional e apresentou seus estudos sobre a assimilação de imigrantes em periódicos como Revista Mexicana de Sociología, Boletín Bibliográfico de Antropología Americana (publicado pelo Pan American Institute of Geography and History), Acta Americana (criado por Julian Steward e publicado pela Inter-American Society of Anthropology and Geography). Além disso, no ano de 1946 reeditou o seu livro de 1940, agora sob o título A aculturação dos alemães no Brasil (Willems, 1946a). No prefácio, explicou que planejava estudar em profundidade os japoneses, o que não foi possível devido aos desdobramentos da guerra no Brasil. Também naquele ano, o livro de Thomas Lynn Smith (1946) A sociologia da vida rural foi publicado em português, recebendo uma resenha elogiosa de Willems (1946b), que ansiava pela difusão da sociologia rural no país.

Outros dois acontecimentos importantes ocorridos naquele ano foram a criação do Departamento de Ciências Sociais da UNESCO e o início das atividades de uma Comissão Nacional da agência no Brasil, denominada Instituto Brasileiro de Educação, Ciência e Cultura (IBECC), por meio do Decreto 9.355 de junho de 1946. O IBECC era sediado no Palácio do Itamaraty, vinculado ao Ministério das Relações Exteriores e posicionou o Brasil no rol dos países-membro que buscavam seguir certos preceitos de desenvolvimento educacional, científico e cultural apregoados pela agência. Um dos responsáveis por sua criação foi o engenheiro e diplomata Paulo Carneiro (Abrantes, 2008). 
O estabelecimento dessas instituições impactou de maneira significativa os meios científico e educacional brasileiros. O IBECC deu prosseguimento a projetos de educação popular interrompidos pela ditadura varguista desde os anos trinta, como a Educação Nova9 ${ }^{9}$, além de realizar pesquisas, produzir e disseminar conteúdos didáticos e abrir novos horizontes para a criação de outras instituições científicas, como o Conselho Nacional de Desenvolvimento Científico e Tecnológico (CNPq), a Sociedade Brasileira para o Progresso da Ciência (SBPC), o Centro Brasileiro de Pesquisas Educacionais (CBPE), a Faculdade Latino-Americana de Ciências Sociais (FLACSO), o Centro Latino-Americano de Pesquisas em Ciências Sociais (CLAPCS). Já o Departamento de Ciências Sociais da UNESCO passou a patrocinar a realização de pesquisas e estimular o intercâmbio de conhecimento em uma escala anteriormente inexistente na sociologia e na antropologia brasileiras. No pós-guerra, as ciências sociais brasileiras se organizavam de maneira bastante dinâmica e a largos passos, caminhando por vias distintas daquela vislumbrada por Willems.

\section{Contendas e os seus significados}

Assim como já havia demonstrado em algumas ocasiões - por exemplo, ao propor, de forma inédita, a aplicação de conceitos da obra de Max Weber para o estudo da burocracia e do patrimonialismo brasileiros, ou ao abordar a questão do antissemitismo antes do término da Segunda Guerra - Willems almejava oferecer novos horizontes para as ciências sociais. Propunha o diálogo da antropologia com a sociologia e a psicologia, quando muitos antropólogos brasileiros notáveis, como Arthur Ramos (que posteriormente foi nomeado diretor do Departamento de Ciências Sociais da UNESCO), ainda não se haviam desvencilhado das classificações antropométricas na caracterização de grupos estrangeiros, conforme bem notou Seyferth (2004). É em reconhecimento ao trabalho de Willems que Ramos afirmou:

9 Ver o Manifesto dos Pioneiros da Educação Nova, de 1932, de autoria do sociólogo e educador Fernando de Azevedo. 
Alguma coisa já foi intentada, sendo de destacar as contribuições de Herbert Baldus e Emílio Willems sobre o grupo japonês, e as monografias fundamentais do prof. Willems sobre o grupo alemão e sua aculturação no Brasil. Esses trabalhos inauguram na realidade, um novo setor, e dos mais importantes, da antropologia brasileira (Ramos, 1948, p. 220).

Parecia não haver muitas dúvidas sobre a centralidade de Pierson, Willems e de outros docentes estrangeiros no restrito meio acadêmico das ciências sociais paulistas. Os dois haviam alcançado posições de destaque nas recém-estabelecidas instituições de ensino, coordenavam projetos de pesquisa, editoravam publicações e estabeleciam um diálogo com o meio acadêmico internacional. Contudo, em fins dos anos quarenta, essa posição aparentemente estabelecida sofreu abalos, iniciados por uma sorte de ampliação (talvez não esperada) dos horizontes das ciências sociais, por meio das atividades desenvolvidas pela UNESCO e, em nível local, pela recepção negativa do livro de Willems intitulado Cunha. Destarte, o regime de cientificidade por eles vislumbrado, fortemente influenciado pela antropologia e pela sociologia estadunidenses, não se viria a se estabelecer da maneira desejada.

Em meio à rivalidade de projetos acadêmicos (mas também de posições políticas) ${ }^{\mathbf{1 0}}$ que se instaurou entre a ELSP e a FFCL (Jackson, 2007), o sociólogo em ascensão Florestan Fernandes elaborou críticas incisivas aos "estudos de comunidades", a partir da recepção negativa de Caio Prado Jr. a Cunha, muito embora tenha reservado elogios a $A$ aculturação dos alemães no Brasil, visto que, em 1944, deu início a um projeto de pesquisa para investigar a aculturação dos sírios e libaneses (Fernandes, [1956] 2010). Em 1948, sua dissertação de mestrado A organização social dos Tupinambá (Fernandes, 1949) foi vencedora do Prêmio Fábio Prado, concorrendo com Cunha. Ao longo dos anos, as diferenças entre Fernandes e os intelectuais estrangeiros se tornaram manifestas, mesmo que muitos deles tivessem sido seus mestres. No trecho a seguir, escrito após assumir a cadeira de Sociologia

10 Àquela época, além de suas atividades acadêmicas, Fernandes também havia se filiado ao Partido Socialista Revolucionário (PSR) e aderiu à militância socialista. 
I na Universidade de São Paulo, Fernandes explicitou seu desconforto em relação à influência estrangeira na sociologia brasileira:

A significação do desenvolvimento da sociologia em nosso meio precisa ser interpretada em termos de sua importância dinâmica para a integração da especialidade à cultura brasileira. Não trabalhamos para os sociólogos europeus ou norte-americanos, senão indiretamente e como contingência da própria natureza do labor científico. (Fernandes, [1956] 2010, p. 240).

Sem a pretensão de explorar a variedade de discussões sobre a obra e a trajetória de Florestan Fernandes, neste artigo sublinho um dado específico, porém significativo para a tarefa de analisar o desenvolvimento dos estudos sobre imigrantes nas ciências sociais brasileiras: a partir dos anos cinquenta, após realizar um estudo sobre relações raciais para a UNESCO e assumir uma posição docente na FFCL, Fernandes foi um dos principais responsáveis por oferecer novos quadros de análise para o estudo da imigração. O autor atribuiu novos sentidos à imigração na formação da sociedade brasileira, bem como promoveu um certo distanciamento das interpretações centradas no contato cultural para se aproximar de uma interpretação interessada na questão do desenvolvimento capitalista e na formação de classes sociais (Brasil Jr., 2010).

Inicialmente, as objeções de Florestan Fernandes ao projeto acadêmico conduzido por Donald Pierson e Emílio Willems foram expressas por uma discussão em que o autor explicitou as diferenças de orientação metodológica entre a antropologia cultural e a sociologia na explicação do comportamento humano, assim como se viu mais inclinado a uma abordagem sociológica proposta Luiz de Aguiar Costa Pinto e defendeu a validade da utilização do conceito de classes sociais. A indagação a seguir sumariza o teor do seu questionamento: "as modalidades de participação da cultura explicam o aparecimento das estruturas sociais, ou são estas que determinam as formas sociais de transmissão da cultura?" (Fernandes, 1948, p. 102). Posteriormente, outros intelectuais ligados a Fernandes, como Octávio lanni (1961a) e Maria Sylvia de Carvalho Franco (1963) e também Luiz de Aguiar Costa Pinto 
(1963) reforçaram essas críticas, e a isso se somou o declínio institucional da ELSP, em grande parte devido à partida de seus docentes estrangeiros e ao minguamento de recursos para a realização de pesquisas. $\mathrm{O}$ trecho a seguir sumariza aspectos centrais dessas críticas:

Em Cunha, por exemplo, que é um estudo pioneiro no Brasil (...) encontra-se o que, a nosso ver, é uma das limitações inerentes ao modelo de pesquisa que estamos examinando (...) Quando, ao final, o autor ordena de par em par os fatores responsáveis pela estabilidade e pela instabilidade da estrutura sociocultural, não ficamos sabendo qual é o encadeamento dinâmico entre os fatores ou as condições das transformações. Como já observou Florestan Fernandes, "as interpretações desenvolvidas param nos limites da caracterização empírica do funcionamento atual da estrutura social e da cultura" (lanni, 1961a, p. 112).

As disputas que caracterizaram o contexto de formação da sociologia paulista já têm sido examinadas pela literatura ${ }^{11}$, sendo oportuno enfatizar o seguinte ângulo: mesmo que tais críticas mirassem em particular a obra Cunha, concebendo-a como expoente dos "estudos de comunidades", elas reverberaram outrossim no modelo de análise das mudanças culturais que Willems propôs para os imigrantes - o que favoreceu o progressivo questionamento da abordagem assimilacionista, quando não para a retenção seletiva de sua contribuição ao desenvolvimento das ciências sociais brasileiras. Ocorre que, na obra de Willems, esses dois tipos de estudos foram combinados de forma a que sua análise pudesse comportar a diversidade de grupos sociais presentes nas áreas rurais do país.

A busca pelo estabelecimento de um instrumental teórico-metodológico vigoroso voltado à interpretação dos fenômenos que afetavam a vida dos imigrantes singularizou a produção acadêmica profissional dos anos quarenta. Na década seguinte, outras propostas investigativas e novos entendimentos sobre a condição do imigrante na sociedade brasileira foram levados adiante, indicando mudanças de quadros de análise que foram capazes de reconfigurar as formas de apreensão das relações étnico-raciais. A esse

11 Ver, por exemplo, Jackson (2009), Oliveira e Maio (2011). 
respeito, as iniciativas de pesquisa patrocinadas pela UNESCO tiveram importância significativa e merecem ser revisitadas.

Na literatura especializada, especial atenção tem sido conferida à atuação e ao protagonismo de personagens centrais nas atividades científicas dessa agência - a exemplo de brasilianistas e de cientistas sociais brasileiros. Isso é notável para o caso dos estudos da UNESCO sobre relações raciais, iniciados em 1950 (Guimarães, 2007; Maio, 1999a, 1999b, 2008; Pereira; Sansone, 2007), ou mesmo para o caso de iniciativas de preservação do patrimônio natural, como o Projeto do Instituto Internacional da Hileia Amazônica (IIHA), formulado em 1947, no âmbito do IBEEC (Petitjean; Domingues, 2001). No Brasil, a maior parte das pesquisas dedicadas a examinar os estudos patrocinados pela UNESCO entre os anos 1940 e 1960 esteve, até os dias atuais, centrada no tema das relações raciais. É inegável a contribuição dessas pesquisas para a o debate acadêmico atual, porém, elas foram capazes de produzir uma narrativa comumente disseminada: de que os estudos patrocinados pela agência intergovernamental sobre a sociedade brasileira são sinônimos de estudos sobre relações raciais - avaliação que desconsidera a sua coexistência com outros projetos de investigação, como aqueles dedicados à imigração e à educação. Visando contribuir com essa literatura, reavalio os estudos conduzidos no Brasil em sua diversidade, de forma a que outros temas de interesse da agência naquele período sejam examinados.

\section{Universalismo ambicionado: imigração e raça no Projeto de Tensões}

Com exceção do trabalho de Mösslinger (2016), até os dias atuais pouca atenção foi conferida aos estudos sobre imigrantes conduzidos pela UNESCO, em que foram investigadas nações como Brasil, Estados Unidos, Reino Unido, Austrália, Israel, Argentina. O planejamento desses estudos teve início em 1947 e os seus principais resultados foram publicados em volumes como Cultural assimilation of immigrants (IUSSP, 1950), Personnes déplacées (Murphy, 1955), The positive contribution by immigrants (Handlin, 1955) (em que Emílio Willems redigiu um capítulo 
sobre o caso brasileiro) e The cultural integration of immigrants (Borrie; Diégues Jr., 1959). Considerando o conteúdo dessas obras em relação às condições institucionais e à intencionalidade de agentes, é pertinente apresentar algumas informações centrais que descrevem o interesse dessa agência intergovernamental no tema da imigração.

Meses após o término da Segunda Guerra, em novembro de 1945, apoiada em valores igualitários e universalistas, a UNESCO se estabeleceu como uma agência especializada do sistema da Organização das Nações Unidas (ONU), voltando-se à promoção e à difusão de conhecimento. $\mathrm{Na}$ avaliação de Maurel (2006), sua criação foi desdobramento de uma iniciativa anterior: a International Institute of Intellectual Cooperation (IIIC), instituição ativa entre 1925 e 1946 e pertencente à Liga das Nações ${ }^{12}$. A UNESCO, então, sucedeu o IIIC, porém visando ampliar seu escopo de atuação e seu alcance. Por isso, na década de cinquenta, a agência teve importância central na criação de instituições científicas internacionais, como o Conselho Internacional de Ciências Sociais (ISSC); a Associação Internacional de Ciência Política (IPSA); a Associação Internacional de Sociologia (ISA); a Associação Internacional de Economia (IEA); o Conselho Internacional para a Filosofia e Estudos Humanos (CIPSH); e o Conselho Internacional de Uniões Científicas (ICSU).

Dentro do sistema das Nações Unidas, outras organizações estabeleceram projetos de auxílio à imigração, em parceria com a UNESCO - como a Comissão Econômica para a América Latina e o Caribe (CEPAL), a Organização das Nações Unidas para a Alimentação e a Agricultura (FAO), a Organização Internacional do Trabalho (OIT) e a Organização Internacional dos Refugiados (OIR) -, muito embora o seu Departamento de Ciências Sociais, criado em 1947, tenha inicialmente centralizado a execução e o planejamento desses estudos. Esse departamento passou a financiar e estimular uma variedade de iniciativas interessadas na superação das consequências recentes da guerra, dentre as quais tiveram destaque os 12 Para mais informações, ver Laqua (2011). 
estudos sobre conflitos, personalidade e sobre relações étnico-raciais em diversos países (Maio, 1999a; Petitjean, 2001).

Ao examinar as atividades desse departamento até 1956, Rangil identificou duas orientações gerais que as conduziram, em obediência à noção de neutralidade apregoada pela UNESCO: universalismo e pluralismo. A noção de "neutralidade" é definida pela autora como "a separação entre os resultados científicos produzidos e divulgados pela organização e a promoção de interesses de potências nacionais particulares" (Rangil, 2011, p. 4) um ideal dificilmente alcançado na prática, mas considerado necessário à época para a legitimação da ciência. A primeira orientação, predominante entre 1946 e 1950, pode ser resumida na ideia de que, para alcançar a neutralidade, os cientistas sociais deveriam produzir um corpo de práticas científicas e conhecimentos universais (fatos, leis, prescrições) compartilhável e aplicável por cientistas sociais de todas as nações. Já a segunda orientação, predominante entre 1950 e 1956, baseou-se na ideia de que a neutralidade poderia ser alcançada se as ciências sociais abrangessem as variedades de práticas científicas, evitando a hegemonia de abordagens, teorias, métodos e prescrições. Na avaliação da autora, por mais que essas orientações aparentassem ser neutras, ambas foram guiadas por vieses políticos e interesses.

No período em que houve predominância da orientação universalista (ou seja, em seu início), o Departamento de Ciências Sociais da UNESCO sofreu influência das abordagens e temas de pesquisas em voga na psicologia social estadunidense, principalmente os estudos de personalidade e de valores nacionais. Neles, buscavam-se explicações para os acontecimentos sociais (como os conflitos e as guerras) a partir de leituras psicoculturais consideradas universais. Justamente essa orientação foi aplicada no principal projeto de pesquisa do Departamento até o início dos anos cinquenta, o Tensions Affecting International Understandings, ou simplesmente Projeto de Tensões.

Ele foi concebido em 1947, por Edward Shils, sociólogo da Universidade de Chicago, e teve Hadley Cantril, psicólogo da Universidade de Princeton, como o seu primeiro coordenador. Este último e o psicólogo e cientista político russo Nathan Leites tiveram importância central na criação do 
Departamento de Ciências Sociais. A realização do Projeto de Tensões foi decidida por meio de uma resolução aprovada na Primeira Conferência Geral, realizada em Paris no ano anterior. Os seus objetivos foram declaradamente favoráveis à compreensão das tensões sociais que formariam as bases da intolerância entre grupos, oferecendo propostas de convivência social pacífica, tendo em vista as recentes atrocidades ocorridas durante a Guerra ${ }^{13}$.

Com a anuência estadunidense, a eliminação de tensões nacionais e étnico-raciais foi um dos principais objetivos a serem alcançados pelo Projeto de Tensões, pois representava, no âmbito da produção de conhecimento, uma possível forma de evitar conflitos entre grupos de origens e costumes distintos. Muito embora o primeiro diretor do departamento, o sociólogo Arvid Brodersen, fosse norueguês, a influência norte-americana ali era perceptível, pois Shils, Cantril e Leites haviam anteriormente trabalhado em serviços de inteligência dos Estados Unidos durante a Segunda Guerra ${ }^{14}$.

No planejamento original do projeto, cinco temas de pesquisa (nacionalismo e internacionalismo, problemas populacionais, problemas raciais, problemas culturais e ideológicos e tensões tecnológicas) seriam investigados por seis áreas de conhecimento (ciência política, economia, sociologia, antropologia, geografia humana e psicologia) ${ }^{15}$. Acatando sugestões do Conselho Econômico e Social (ECOSOC) - instância à qual a UNESCO é subordinada - e da Comissão dos Direitos Humanos (UNCHR) da ONU, a orientação institucional do Departamento de Ciências Sociais esteve, desde o início de suas atividades, explicitamente focada na imigração e na superação do racismo e do preconceito $^{\mathbf{1 6}}$.

Isso estimulou a realização de programas originais de estudos não somente sobre relações raciais, mas também sobre minorias de outras nacionalidades.

${ }_{13}$ Preliminary outline of project on Tensions affecting international understanding. UNESCO/ Soc.Sci/2/1947. Paris, 12 de maio de 1947.

${ }^{14}$ Mais especificamente, o Office of Strategic Services (OSS), precursor da CIA e o Office of War Information (OWI).

${ }^{15}$ Further Analysis of the "Tensions Crucial to Peace" Project. Analytical breakup. Tensions Affectioning International Understandings - Part I up to 1947. Box 327.5.

${ }^{16}$ Economic and Social Council. Official Records, Supplement $n^{\circ} 13$. Report on the first session of the Economic Commission for Latin America, 1948. Ver também: Correspondência de John Humphrey a André de Blonay, 28 de novembro de 1947. UNESCO Archives. 
Principalmente os estudos sobre racismo, preconceito e estereótipos foram assistidos pela Subcomissão de Prevenção à Discriminação e Proteção de Minorias, um quadro de especialistas subordinado à UNCHR, criado em agosto de 1947. Em meio a esse cenário institucional, em maio de 1948 o diretor do Departamento Arvid Brodersen comunicou que os planos de estudos sobre preconceito racial seriam incluídos no quadro do Projeto de Tensões ${ }^{17}$, tornando-se uma área de investigação, além daquelas já então previstas, que já incluíam a assimilação cultural de imigrantes (Klineberg, 1949).

Portanto, assim como a raça, a imigração foi um dos temas de interesse dos primeiros estudos conduzidos pelo Departamento de Ciências Sociais da UNESCO. Ambos foram originalmente abrigados no projeto central do departamento, o Projeto de Tensões, cujo objetivo era conceber formas de se evitar a ocorrência de conflitos. Ao menos até $1951^{18}$ - quando as pesquisas sobre no Brasil tiveram início - , tanto o tema da raça quanto o da imigração ali coexistiram ${ }^{19}$.

\section{A participação brasileira na fase pluralista do Departamento de Ciências Sociais da UNESCO}

Em 1948, os planejadores do Projeto de Tensões estabeleceram um primeiro contato com departamentos de ciências sociais brasileiros. Esse dado esteve ausente na literatura, e o seu exame nos permite adentrar um universo de eventos significativos do processo de constituição da sociologia brasileira e de suas disciplinas congêneres.

Em Paris, no mês de abril daquele ano de 1948, o Departamento de Ciências Sociais da UNESCO produziu o relatório The human sciences and world peace, que, seguindo as orientações da Segunda Conferência

${ }^{17}$ Correspondência de Avid Brodersen ao setor de Relações Exteriores. 28 de maio de 1948. Box 323.1 Race questions and protection of minorities - Part I up to 1950. UNESCO Archives.

${ }^{18}$ Correspondência de André de Blonay (Chefe de relações externas) a John P. Humphrey (Diretor da Divisão de Direitos Humanos da ONU), 28 de novembro de 1947. Box 323.1 Race questions and protection of minorities - Part I up to 1950. UNESCO Archives.

${ }^{19}$ Ver Angell, 1950. 
Geral, estabelecia as resoluções específicas para a condução do Projeto de Tensões. No mês seguinte, foi redigido um esboço contendo os planos para a execução de suas atividade ${ }^{20}$, que incluía a realização de uma conferência com especialistas entre os meses de junho e julho, para discutir as formas de evitar predisposições de nacionalismo agressivo. Desse encontro, resultou a declaração A statement by eight distinguished social scientists on the causes of tensions which make for war ${ }^{21}$, que atribuía às ciências sociais um importante papel no estabelecimento da paz e do entendimento entre povos e nações, e teve Gilberto Freyre como um de seus distintos signatários.

Mesmo que o Brasil já participasse de outras iniciativas patrocinadas pela agência - a exemplo das já mencionadas pesquisas sobre a Hileia amazônica e de projetos educacionais e de alfabetização - , a reputação internacional de Freyre contribuiu para consolidar uma imagem possivelmente exemplar da sociedade brasileira no que se refere à convivência pacífica entre grupos e o pressuposto da inexistência do racismo (Maio, 1999a). Além do alcance internacional de sua obra, o mito da "democracia racial" 22 se tornou uma prática recorrente no plano discursivo, principalmente no contexto brasileiro de redemocratização, após o fim do regime político do Estado Novo (193745). Por sua vez, a UNESCO vivia o dilema de defender direitos humanos universais e, ao mesmo tempo, respeitar a vigência do sistema colonial europeu, lidar com o início do regime de apartheid na África do Sul e a segregação racial nos Estados Unidos. O Brasil era visto, assim, do ponto de vista de uma anunciada singularidade.

Com o objetivo de recrutar cientistas sociais brasileiros que pudessem colaborar com a execução do Projeto de Tensões, também em junho daquele ano, Arvid Brodersen estabeleceu um primeiro contato com

20 Outline of plan for the execution of the project "Tensions affecting international understanding" and report of progress to 15 May 1948. UNESCO Archives.

${ }^{21}$ Foram signatários: Gilberto Freyre, Gordon Allport, Georges Gurvitch, Max Horkheimer, Arne Naess, John Rickman, Harry Stack Sullivan e Alexander Szalai.

22 Para mais detalhes sobre a ideia de "democracia racial", ver Guimarães (2006). O autor interpreta a "democracia racial" considerando a formulação de um projeto nacionalista, tanto em termos econômicos quanto culturais, sendo assim um pacto social, um compromisso racial e de classes sob bases material e simbólica, conduzido pelo Estado brasileiro. 
o Departamento de Sociologia e Antropologia da Universidade de São Paulo. Esse contato foi possivelmente facilitado pelo psicólogo canadense da Universidade de Columbia, Otto Klineberg (1899-1992), que em 1949 assumiu a direção do Projeto de Tensões. Anos antes, entre 1945 e 1947, ele havia sido contratado pela Universidade de São Paulo e colaborou com a criação do Departamento de Psicologia da instituição. Posteriormente, trabalhou mais alguns anos no Brasil no âmbito do IBECC.

Em 1948, a FFCL estabeleceu contato como a UNESCO e apresentou um levantamento de instituições e pesquisadores brasileiros que estavam dispostos a colaborar com o Projeto de Tensões, mais especificamente com suas resoluções que recomendavam: a realização de investigações sobre imagens que populações nacionais possuem em relação às outras (Res. 5.1.1.2); investigações sobre técnicas em educação, ciência política, filosofia e psicologia para a mudança de atitudes (Res. 5.1.1.3); investigações sobre influências que resultam em compreensão internacional e também em nacionalismo agressivo (Res. 5.1.1.4). A seguir, reproduzo trechos do relatório, que não deixou de ressaltar que seus pesquisadores estavam envolvidos com a produção de estudos de comunidades e estudos de assimilação e aculturação:

Em julho e agosto vários membros deste Departamento foram ao Rio de Janeiro e a Belo Horizonte para listar pessoas e instituições que desejam colaborar no projeto de Tensões. [...] Algumas resoluções do Projeto de Tensões podem ser conduzidas pelo Departamento de Sociologia e Antropologia da Universidade de São Paulo. No presente momento, o quadro do Departamento é composto pelas seguintes pessoas Fernando de Azevedo, Roger Bastide, Emílio Willems, Lourival Gomes Machado, Antonio Candido de Melo e Souza, Gilda Melo e Souza, Florestan Fernandes, Egon Schaden, Gioconda Mussolini, Lavínia Costa Vilela. Trabalho de campo em comunidades rurais e urbanas, problemas de assimilação e aculturação têm sido conduzidos e publicados pela maioria dos membros do Departamento (UNESCO, 1948, p. 1-2, tradução minha).

Além de colocar à disposição seu corpo docente e de pesquisa, a FFCL listou outras instituições interessadas no projeto, embora, nos anos seguintes, tenha sido ela a estabelecer um vínculo mais imediato com a UNESCO 
na área da sociologia. Isso ocorreu por meio das pesquisas sobre relações raciais em São Paulo e também pelo envolvimento de seus membros em instituições científicas, das quais destaco aqui a Sociedade Brasileira de Sociologia (SBS) ${ }^{23}$, criada em março de 1950 e presidida pelo sociólogo e educador Fernando de Azevedo, da FFCL. Este já havia sido convidado pela International Sociological Association, no ano anterior, para a solenidade de sua fundação, patrocinada pela UNESCO, visto que Azevedo ocupou cargo o Vice-Presidente da associação entre 1950-53. Em 1950, um convite foi feito ao Departamento de Sociologia e Antropologia da FFCL para que esta enviasse participantes ao I Congresso Mundial de Sociólogos, ocorrido no mês de setembro, em Zurique, Suíça ${ }^{24}$. Com o estímulo da UNESCO, o tema das tensões sociais foi acolhido no debate sociológico internacional.

O congresso teve como tema Sociological research in its bearing on international relations, e comportou três subtemas: questões metodológicas, características e atitudes nacionais e aspectos sociológicos das relações entre nações. Foram cinco os participantes de instituições brasileiras: Fernando de Azevedo, Florestan Fernandes, José Arthur Rios e Mário Lins. Roger Bastide submeteu o trabalho Assimilation culturelle et nationalisme, mas não compareceu ao evento. Já Florestan Fernandes apresentou o trabalho Considerações sobre a aplicação dos conhecimentos sociológicos às relações internacionais. $\mathrm{O}$ autor procurou explicitamente dialogar com a agenda da discussão sociológica assistida pela UNESCO, centrada no tema das tensões:

Neste artigo, tentei analisar se os sociólogos podem contribuir para o estudo e a solução das tensões e conflitos existentes no mundo atual [...] Ela pode servir à diplomacia com seu conhecimento científico e técnicas operacionais no tratamento de 'problemas sociais', reduzindo as tensões e conflitos internacionais (Fernandes, 1950, p. 3).

${ }^{23}$ A Sociedade Brasileira de Sociologia foi criada em 1950 como desdobramento da Sociedade de Sociologia de São Paulo, criada em 1937. A sua sede inicial foi instalada na FFCL, dispondo também de seções regionais no Rio de Janeiro e Recife (Miceli, 2001).

${ }^{24}$ O Estado de S.Paulo, 13 de abril de 1950, p. 7. 
No mesmo congresso, o sociólogo polonês Shmuel Eisenstadt apresentou os resultados de suas pesquisas realizadas em parceria com a UNESCO sobre imigrantes da diáspora judia em Israel, com o trabalho Research on the cultural and social adaptation of immigrants. Adiante veremos que a perspectiva de Eisenstadt marcou significativamente a forma como Fernandes interpretou a imigração na formação da sociedade brasileira.

Ainda em 1948, Gilberto Freyre foi convidado para assumir a direção do Departamento de Ciências Sociais da UNESCO tendo, contudo, declinado o convite (Maio, 1999b, p. 114). No ano seguinte, ocupou o cargo o médico e antropólogo Arthur Ramos que, desde 1946, era catedrático de Antropologia da Faculdade Nacional de Filosofia da Universidade do Brasil. Junto de Arthur Costa Pinto e Alfred Métraux, Ramos delineou a execução das pesquisas sobre raça no Brasil entre 1950 e 1953 (Maio, 1997,1999a; Guimarães, 2008), aprovada na Conferência Geral do ano seguinte.

Em dezembro de 1949, uma reunião específica sobre o tema foi realizada, congregando cientistas eminentes como Claude Lévi-Strauss. Disso resultou a conhecida Declaração sobre raça, publicada em 1950 (Maio; Santos, 2010). Esse primeiro encontro ocorreu sob os auspícios do Projeto de Tensões, conforme revelou o jurista catalão Josep Xirau, secretário do encontro: "De fato, foi a Divisão de Tensões que forneceu os fundos para a organização do encontro de especialistas em problemas da raça"25. A essa iniciativa, sucederam-se outras reuniões, assim como as pesquisas sobre relações raciais no Brasil (realizadas nas cidades de Salvador, Rio de Janeiro, São Paulo e Recife) foram melhor planejadas, em parte aproveitando os vínculos institucionais e as condições implementadas em projeto já em execução pela Revista Anhembi e pelo Programa de Pesquisas Sociais - Estado da Bahia/Columbia University (Guimarães, 2007).

O falecimento de Arthur Ramos, três meses após assumir a direção do Departamento de Ciências Sociais da UNESCO, em outubro de 1949,

${ }^{25}$ Correspondência de J. R. Xirau a Robert Angell. SS/Memo/1391/21 de dezembro de 1949. Box 323.1 Race questions and protection of minorities - Part I up to 1950. UNESCO Archives. 
fez com que o sociólogo estadunidense da Universidade de Michigan e capitão da aeronáutica dos Estados Unidos, Robert Cooley Angell (18991984) assumisse temporariamente o cargo. Assim como seu tio, o sociólogo Charles Horton Cooley, Robert Angell também ocupou a presidência da American Sociological Association (ASA) em 1951, e foi o segundo presidente da International Sociological Association (ISA), entre 1953-56. Na direção do Departamento, ele foi sucedido pela socióloga e diplomata sueca Alva Reimer Myrdal, esposa do economista e sociólogo Gunnar Myrdal, conhecido por seus estudos sobre relações raciais nos Estados Unidos. Posteriormente, Alva e Gunnar foram laureados com o prêmio Nobel.

O trânsito de diretores de projetos e de diretores do Departamento de Ciências Sociais da UNESCO até fins de 1950 revela uma fase incipiente de institucionalização, caracterizada por um quadro reduzido de funcionários, recursos limitados e indefinições das práticas investigativas, embora certas configurações de poder possam ser evidenciadas.

Seguindo a interpretação de Rangil, se, no período de 1946 a 1950, houve ali a predominância estadunidense não somente do ponto de vista acadêmico, mas também de interesses estratégicos, uma fase subsequente se mostrou consideravelmente distinta. Principalmente sob a direção de Alva Myrdal, foi enfatizada uma orientação pluralista, que teve sucesso em atrair um corpo de membros mais heterogêneo, com formações acadêmicas diversas, incluindo pesquisadores não saxões. Entre os seus desdobramentos, é possível destacar, no âmbito do Projeto de Tensões, uma ênfase específica no tema da raça do ponto de vista antropológico e sociológico, assim como uma tendência geral à mudança de orientação, do enfoque psicológico para as tensões sociais e econômicas:

Após 1950, o Departamento mudou sua orientação, o Projeto de Tensões foi dividido em vários subprojetos que ganharam autonomia e foram incluídos outros programas sobre tensões sociais, como as pesquisas sobre preconceito racial e trabalhos de assistência técnica a países menos desenvolvidos (RANGIL, 2011, p. 9, tradução minha). 
Sobretudo, mesmo que esse projeto tenha sofrido alterações no decorrer dos anos, tratou-se de uma iniciativa de pesquisa de envergadura internacional e que alcançou departamentos de sociologia e antropologia recém-estabelecidos, a exemplo do caso brasileiro. Mais ainda, esse projeto constitui um ponto de partida para pesquisadores interessados no exame detalhado dos eixos de investigação que se originaram a partir dele. A análise documental não nos deixa dúvidas de que os estudos sobre imigração conduzidos pela UNESCO ocorreram no escopo das atividades do Projeto de Tensões:

Estudos sobre assimilação cultural de imigrantes constituem parte do 'Estudo de Tensões' incluídos no programa de Ciências Sociais da UNESCO. O propósito desses estudos é avançar nosso conhecimento sobre fatores que provavelmente afetarão crises sociais que, se agravadas, podem comprometer a paz (UNESCO, 1950a, p. 1, tradução minha).

\section{Estudos sobre imigrantes e iniciativas de suporte à imigração em âmbito internacional}

Ao longo dos anos cinquenta, um dos principais eixos de investigação do Projeto de Tensões permaneceu sendo o de traços nacionais, pois, por meio deles, seus formuladores acreditavam ser possível compreender as tensões entre diferentes valores e crenças e, assim, evitar comportamentos hostis entre grupos e nações. Algumas das principais publicações nesse sentido foram Tensions affecting international understanding: a survey of research (1950), de Otto Klineberg, e Without the chrysanthemum and the sword: a study of the attitudes of youth in postwar Japan (1955), de autoria do sociólogo francês Jean Stoetzel.

Em relação ao eixo de estudos sociológicos e antropológicos sobre imigração (assim como aqueles sobre raça), a UNESCO adotou uma série de procedimentos preliminares de maneira a sancionar a realização de pesquisas e relatórios. A primeira medida básica foi a aprovação de uma resolução (4.315), na Terceira Conferência Geral da UNESCO, ocorrida em 1948, a partir da qual, o Diretor-Geral foi instruído a promover investigações 
sobre o tema da assimilação cultural de imigrantes na área das ciências sociais. Isso autorizou a realização de iniciativas diversas, como conferências específicas ${ }^{26}$ e a realização de parcerias com órgãos não governamentais e agências especializadas visando à formulação de políticas migratórias e o desenvolvimento de técnicas de análise demográfica. Ademais, o Conselho Econômico e Social buscou centralizar o planejamento de atividades a partir de uma comissão especial, o Working Group on Migration, criado em 1950.

Portanto, do ponto de vista organizacional, a UNESCO passou a produzir conhecimento sobre o tema da imigração mediante parcerias internas e externas ao sistema ONU. No primeiro caso, isso incluiu outras agências especializadas, como as já mencionadas OIT, FAO e OIR. No segundo caso, as parcerias ocorreram principalmente com governos e órgãos especializados em imigração. Uma das instituições significativas sob esse aspecto foi a International Union for the Scientific Study of Population Problems (IUSSP) ${ }^{27}$, valorizada por sua experiência de décadas no assunto. Em reunião ocorrida naquele ano, a IUSSP se afirmou como um centro não governamental para discussões sobre imigração no imediato pós-guerra, sendo financiada pela Fundação Rockefeller e pelo governo francês. Já a UNESCO patrocinou essa instituição solicitando a produção de relatórios e a organização de conferências (Kiser, 1950).

A despeito de sua relevância, a IUSSP era composta por membros que, em sua maioria, não eram oriundos de meios profissionais estritamente acadêmicos como universidades, departamentos e centros de pesquisa. Devido a essa composição, o conteúdo que foi ali produzido priorizou a aplicação de conhecimento com objetivos bastante pragmáticos: assistência às políticas migratórias, apoio a refugiados, alocação no mercado de trabalho e programas educacionais. Por sua vez, as análises sociológicas

${ }^{26}$ São exemplos disso os eventos The International Conference of Non-Govermnental Organizations interested in Migration, ocorrida em 1950 em Geneva, a International Population Conference, ocorrida em 1954 em Roma com patrocínio da ONU e em parceria com IUSSP. ${ }^{27}$ Fundada originalmente em 1928, em decisão ocorrida na Conferência Internacional de Populações, ocorrida no ano anterior em Genebra, Suíça. Após a Segunda Guerra, foi reformulada, e em 1947 contava com 147 membros de 32 países. 
de viés estritamente acadêmico eram, em geral, planejadas com consulta a especialistas, dentre os quais podemos destacar o sociólogo e demógrafo britânico David Glass, um dos fundadores do Population Investigation Committee (PIC), centro de pesquisas ligado à London School of Economics, o historiador estadunidense Oscar Handlin, da Universidade de Harvard, o geógrafo francês Georges Mauco, o demógrafo italiano do IBGE Giorgio Mortara, entre outros. As suas sugestões para o planejamento de pesquisas eram, em muitos casos, direcionadas para a recém-criada International Sociological Association, que passou a promover simpósios e grupos de trabalho, além de publicar resultados de pesquisas em revistas especializadas, principalmente a International Social Science Bulletin.

Os documentos que reportam as atividades do Departamento de Ciências Sociais da UNESCO a partir de 1950 indicam que houve uma progressiva consolidação do aparato institucional voltado à produção de conhecimento sobre o tema da imigração, e a isso se somou a orientação pluralista conduzida por Alva Myrdal. Essa configuração teve desdobramentos significativos no desenvolvimento de quadros teórico-metodológicos. Naqueles anos, mais especificamente nos relatórios e conferências produzidos entre 1950 e 1956, especialistas formularam novas definições de categorias centrais para a análise sociológica e antropológica de fenômenos migratórios: raça, etnia, assimilação, integração. Essas novas acepções eram menos tributárias da internacionalmente conhecida tradição teórica de Chicago com foco no contato cultural, tão prezada por Emílio Willems no Brasil. O debate sobre imigração na UNESCO, então, progressivamente se adequou à temática emergente do desenvolvimento econômico e social, bem como encorajou formas de convivência pacífica mediante o reconhecimento das diferenças culturais de grupos imigrados. Nesse contexto, o caso de Israel se destacou a partir de pesquisas dedicadas.

Desde 1947, o termo "assimilação cultural" vinha sendo utilizado na UNESCO como sinônimo de estudos sobre imigração, representando uma espécie de vocábulo de alcance universal. O principal avanço promovido pela agência ao utilizá-la foi, conforme assinalou Mösslinger (2016), relativizar 
o enfoque malthusiano no debate internacional sobre imigração em curso desde a década de 1920. Após o fim da Segunda Guerra, no âmbito da UNESCO, as explicações causais de fenômenos populacionais de cunho geográfico e biológico não mais se sobrepuseram às interpretações oriundas das ciências sociais. Contudo, a polissemia do termo "assimilação", por diversas vezes, foi questionada por especialistas na tentativa de se alcançar uma definição comum, porém, sem sucesso. Ao longo dos anos, tornou-se evidente que esse termo se tornara demasiadamente amplo e vago por comportar diversos significados e modalidades de manifestação. Em relatórios, autores até mesmo o intercambiavam com outros termos: "integração", "absorção", "adaptação" (UNESCO, 1950b). A alternativa para o impasse foi concebida no terceiro encontro da International Conference of Nongovernmental Organizations Interested in Migration, ocorrida em 1952, com patrocínio da UNESCO e da OIT. Desse encontro, resultou uma declaração publicada em 1954, intitulada The integration of migrants into the life of their countries of resettlement. Observations and practical suggestions, em que o termo "integração" ganhou uma definição específica e passou a ser considerado enquanto processo a ser analisado por excelência nos estudos sobre imigração, em detrimento dos processos de "assimilação" cultural:

A integração dos migrantes foi definida pela conferência como o processo gradual pelo qual os novos residentes se tornam participantes ativos nos assuntos econômicos, sociais, cívicos, culturais e espirituais de uma nova pátria [...] É um processo em que ambos os migrantes e seus compatriotas encontram a oportunidade de fazer suas próprias contribuições" (UNESCO, 1955, p. 2, tradução minha).

A despeito da clara abrangência dessa definição, o fato a ser destacado é que sob a direção de Alva Myrdal o Departamento de Ciências Sociais da UNESCO concebeu a imigração ultrapassando o sentido de simples deslocamento de indivíduos, dando lugar à formação de novas expressões culturais em contextos nacionais. Myrdal se envolveu diretamente com os estudos de imigração tendo, por exemplo, organizado e dirigido sessões 
temáticas durante a World Population Conference, ocorrida em 1954 em Roma. Sob tal viés, "integração" pressupôs contribuições trazidas pelos imigrantes à sociedade de destino. Não por acaso as edições seguintes de conferências especializadas em imigração foram intituladas Conference on the Cultural Integration of Immigrants, ocorridas em 1955 e 1956 em Caracas e Havana, respectivamente. Desses encontros, resultou o mais completo documento sobre imigração no Brasil produzido pela UNESCO: um manual explicitamente direcionado a órgãos responsáveis pelas políticas migratórias: A draft manual on the cultural integration of immigrants (1959), de autoria de Manuel Diégues Jr. e do reverendo Fernando Bastos d'Ávila.

Nesse contexto, por indicações dos consultores Giorgio Mortara e David Glass, Emílio Willems foi convocado pela UNESCO para produzir um relatório sobre o Brasil no volume The positive contribution by immigrants (Handlin, 1955). Especialista na análise dos processos de aculturação e assimilação de grupos estrangeiros, nesse trabalho, o autor deixou a abordagem assimilacionista em segundo plano e enfatizou os desdobramentos positivos da presença imigrante na economia e na cultura nacional. Além das críticas que o modelo cultural-assimilacionista vinha sofrendo no meio acadêmico brasileiro, Willems se deparou com um novo cenário de produção intelectual: novas abordagens e propostas teóricometodológicas alcançavam reconhecimento no debate internacional, com destaque para os trabalhos de Shmuel Eisenstadt. Ademais, as temáticas da industrialização e do desenvolvimento econômico e social adquiriam cada vez mais centralidade nas agendas de pesquisa de cientistas sociais.

Na década de 1950, os estudos científicos sobre imigração conduzidos pela UNESCO já haviam adquirido contornos específicos, alinhados com valores apregoados pela agência. Essa característica também esteve presente nos estudos sobre raça, cuja origem é partilhada: o Projeto de Tensões. Paulatinamente, esses dois temas tanto se desvincularam desse projeto quanto não ficaram limitados à atuação do Departamento de Ciências Sociais. Mas a forma intrincada pela qual o Projeto de Tensões foi delineado e conduzido ocultou parcialmente a trajetória de tais estudos. Por isso mesmo, 
pesquisadores encontram dificuldades em avaliar os seus desdobramentos para contextos locais, como no caso das ciências sociais brasileiras. Em especial, a articulação entre os dois temas ainda tem sido pouco examinada pela literatura, mesmo que presente em duas pesquisas sobre relações raciais coordenadas por Florestan Fernandes na década de 1950 em São Paulo e em cidades da região Sul do Brasil (Porto Alegre, Florianópolis, Curitiba e Pelotas).

Um livro que se tornou emblemático na sociologia brasileira do pós-guerra nos oferece pistas para melhor compreendermos a referida correspondência: Relações raciais entre negros e brancos em São Paulo Ensaio sociológico sobre as origens, manifestações e os efeitos do preconceito de cor no município de São Paulo, organizado por Roger Bastide e Florestan Fernandes (1955). A publicação contém os resultados das pesquisas sobre raça patrocinadas pela UNESCO realizadas na capital paulista. Os seus capítulos foram publicados originalmente em 1953 na revista Anhembi, dirigida pelo influente Paulo Duarte. No formato de livro, publicado em 1955, foi composto por nove capítulos, de autoria de Florestan Fernandes, Roger Bastide, Aniela Meyer Ginsberg, Oracy Nogueira e Virgínia Leone Bicudo.

É em sua primeira edição que podemos observar, principalmente no capítulo de Bicudo (1955), a tentativa de mensurar o preconceito sob o viés da psicologia social por meio da análise de estereótipos raciais e nacionais. Trata-se das pesquisas de atitudes e de personalidade, que tiveram Otto Klineberg como um dos seus grandes entusiastas. Anos antes, sob influência desse autor, já haviam sido produzidos trabalhos como Uma pesquisa sobre aceitação de grupos nacionais, "raciais" e regionais em S.Paulo, da psicóloga Carolina Martuscelli (1950), Um inquérito sobre as atitudes de estudantes baianos em relação a diversos grupos nacionais e raciais (1950), da psicóloga Aniela Ginsberg, e Um questionário sobre estereótipos raciais (1951), do antropólogo Thales de Azevedo.

Em agosto de 1950, no contexto de elaboração do projeto de relações raciais no Brasil, Klineberg escreveu algumas de suas sugestões às pesquisas sobre raça no Brasil a serem conduzidas com o patrocínio da UNESCO. Naquele ano, ele era um dos consultores do Projeto de Tensões e 
anteriormente havia sido o diretor do projeto. Em sua avaliação, os estudos sobre raça a serem realizados no Brasil deveriam contemplar "outros padrões de relações intergrupos" além do estabelecido entre negros e brancos, como aqueles entre grupos de origem estrangeira. Outra recomendação de seu relatório era que a pesquisa não se restringisse somente à Bahia, conforme fora inicialmente previsto, mas que fossem incluídas outras localidades do país, como a cidade de São Paulo, que comportava uma diversidade de grupos raciais e étnicos (Klineberg, 1950b).

Virgínia Leone Bicudo seguiu essas sugestões. A autora havia assistido alguns cursos do psicólogo canadense na Universidade de São Paulo e já havia demonstrado interesse em colaborar com o Projeto de Tensões. Em seu estudo, considerou a presença de grupos estrangeiros na cidade de São Paulo enquanto um dado relevante para averiguar se as formas de sociabilidade infantil eram constituídas em bases raciais - abordagem interessada em mensurar atitudes segundo critérios de preferências, assim como em medir a intensidade de preconceitos motivados por cor, raça e nacionalidade.

A despeito de sua relevância, hoje cada vez mais reconhecida a partir de estudos dedicados ${ }^{28}$, as interpretações de Bicudo e Ginsberg ocuparam uma posição de menor destaque no debate sobre relações raciais em curso nas ciências sociais brasileiras da década de 1950, enquanto as de Bastide e Fernandes acabaram por se tornar centrais. Conforme o próprio subtítulo do livro sugeria, os organizadores da obra deixaram evidente a preferência pela interpretação sociológica dos fenômenos estudados, almejando uma dimensão explicativa ampla, preterindo então a abordagem psicológica com foco nas atitudes individuais. Ao palestrar sobre o caso dos imigrantes sírios e libaneses em São Paulo, Fernandes afirmou a sua opção:

parece conveniente lembrar que a análise sociológica preenche uma função deveras importante no mundo moderno. Ela contribui para criar uma consciência mais completa e profunda das condições de existência humana (...) como atestam recentes publicações da Unesco, o que se poderia chamar de efeitos positivos da imigração só é suscetível de conhecimento objetivo e preciso mediante a análise sociológica. (Fernandes, [1956] 2010, p. 229).

${ }^{28}$ Ver Maio (2010) e Gomes (2013). 
Do ponto de vista teórico, em seu estudo sobre raça, o autor reportou o caso de São Paulo à UNESCO, a partir de uma abordagem inovadora, que considerou a dimensão histórica do processo de expansão da ordem capitalista na sociedade brasileira, sublinhando a formação de uma nova ordem social de trabalho livre e estruturada a partir de classes. Segundo Guimarães, Florestan Fernandes promoveu

uma reinterpretação da situação racial brasileira em termos 'históricofuncionalistas', politicamente afastada da problemática norte-americana de assimilação cultural e integração do negro à democracia, e voltada, ao contrário, para o ideal nacionalista e desenvolvimentista de redefinição do 'povo brasileiro', por meio da fusão dos conceitos de raça e classe (Guimarães, 1999, p. 77).

Esse movimento de reinterpretação indicava também certa simpatia pela temática emergente do desenvolvimento econômico e social que caracterizou a sociologia latino-americana da época (BRASIL Jr., 2010), o que se expressou com vigor em algumas de suas obras posteriores, como A integração do negro na sociedade de classes (Fernandes, [1978] 2008) e A revolução burguesa no Brasil (Fernandes, 1975).

Neste artigo, destaco que as iniciativas de pesquisa patrocinadas pela UNESCO aqui examinadas representaram um momento singular no desenvolvimento disciplinar das ciências sociais brasileiras do pós-guerra. Elas viabilizaram, de maneira inédita, um intercâmbio de conteúdos em nível internacional, assim como repercutiram no debate sociológico local sobre relações étnico-raciais, em especial no pensamento de Florestan Fernandes. Isso pode ser averiguado em suas interpretações sobre as relações entre negros e brancos, mas também na forma como esse intelectual concebeu o lugar social do imigrante na estrutura social, sustentando a tese de que "[a] imigração se adaptou às inconsistências do sistema brasileiro de relações raciais" (Fernandes, [1965] 2007, p. 131). Em outras palavras, a imigração pouco teria alterado as estruturas de relações raciais na marcha histórica desigual da ordem social competitiva, portadora de barreiras estruturais à integração do negro. Assim, a imigração enquanto fenômeno social foi por ele 
elevada a um outro patamar teórico: um fator indicativo da não linearidade das mudanças em uma sociedade tradicionalista e de desenvolvimento tardio.

\section{A emergência do modelo integracionista nos estudos sobre imigrantes}

Ao avaliar a construção histórica da pluralidade étnica brasileira, o antropólogo João Baptista Borges Pereira destacou a importância da antropologia e da sociologia em sua capacidade de refletir criticamente sobre a representação ideológica contida no modelo pluriétnico atrelado ao mito da democracia racial. Esse modelo foi tipologicamente conceituado como "integracionista no plano estrutural ou social, assimilacionista no plano cultural e miscigenacionista no plano biológico" (Pereira, 2000, p. 9), pressupondo uma velada política de identidade nacional que bloqueia ou elimina eventuais tentativas de preservação de alteridades étnicas ou raciais. Ao mesmo tempo, o autor identificou o viés subjacente às análises científicas sobre imigrantes que automaticamente associa a ideia de integração a movimentos de mobilidade ascensional. Acredito ser possível aprofundar essa pista investigativa, se acompanharmos certos processos de composição e mudança de quadros de análise - em especial a emergência da abordagem integracionista que se disseminou com relativo sucesso nos estudos sobre imigrantes.

Se, por um momento, deixarmos o olhar detido no debate acadêmicocientífico e considerarmos o momento político e social subsequente ao fim do Estado Novo, é possível afirmar, de maneira geral, que no período denominado intervalo democrático grupos sociais passaram a ser paulatinamente reconhecidos e incorporados nos planos político, econômico e cultural, em uma equação capaz de balancear um regime de caráter elitista porém inclusivo em certos aspectos, ao mesmo tempo em que categorias centrais para a construção de direitos e oportunidades como "nação", "democracia" e "inclusão" foram mobilizados por grupos sociais e pelo Estado, adquirindo novos significados. Principalmente metrópoles como São Paulo e Rio de Janeiro experimentaram uma efervescência econômica 
e industrial estimulada por ideias de desenvolvimento que buscaram situálas nos caminhos da modernização (Soares, 1973; Sola, 1998).

Em relação a direitos políticos e ao exercício dos direitos civis, a elaboração da Constituição de 1946 trouxe consigo novidades. Sob forte influência de um léxico trabalhista, partidos políticos nacionais com programas ideológicos definidos e identificados com o eleitorado puderam se reorganizar, o que também possibilitava, ao menos em tese, a progressiva participação política de grupos que até então haviam contado com pouca representatividade. Os efeitos locais dessas grandes mudanças em curso foram expressos, por exemplo, por fenômenos como a reconfiguração da composição populacional, a migração rural-urbana, processos de mobilidade ascendente, a estruturação do mercado de trabalho. Essas significativas transformações econômicas e sociais colocaram como desafio aos sociólogos e antropólogos a recorrente questão da integração de determinados segmentos sociais subalternizados à modernidade. Assim, ao longo dos anos cinquenta e início dos sessenta certos conteúdos considerados inovadores foram absorvidos pelas ciências sociais brasileiras.

Em tal contexto, a noção de "integração" transpôs as possibilidades de conflito entre grupos de origens distintas - antes compreendidas estritamente no plano cultural - para o plano das relações mercantis. A característica competitiva do mercado é que, no plano de análise, constituiria o eixo motriz das formas de organização social. O sucesso ou insucesso dos grupos em se adaptar às suas estruturas, mediante a mobilidade socioeconômica e a inserção em melhores posições na estrutura ocupacional, forneceria indícios de sua integração ao tecido social. Isso representou uma espécie de síntese do debate sobre modernização e do modelo de análise de imigrantes concebido pelo sociólogo polonês Shmuel Eisenstadt. No quadro de pesquisas da UNESCO, a partir de 1948, este último autor e a sua equipe analisaram o caso da formação do Estado de Israel com especial foco nos imigrantes da diáspora judia. Dessa primeira iniciativa resultou outro importante projeto: The Israeli 'Tensions Studies', planejado em 1952, e que contou com o apoio de Arvid Brodersen - o primeiro diretor do Departamento de Ciências 
Sociais da UNESCO. O modelo de análise que Eisenstadt desenvolveu a partir dessas pesquisas combinou metodologias diversas, oriundas da economia, demografia, psicologia e sociologia. Em resumo, buscou mostrar a absorção ou integração dos imigrantes em estruturas institucionais que possibilitavam a diferenciação de grupos e indivíduos, desde que as diferenças não levassem a relações de dominação ou à desunião (Gordon, 1964).

Eisenstadt levou adiante a proposta de criar modelos comparativos para a análise do fenômeno migratório. Para isso, problematizou a validade supostamente universal de índices de assimilação e a sua aplicabilidade em pesquisas comparativas, o que resultou no famoso livro The absorption of immigrants (1954). Para o autor, a assimilação deveria ser concebida enquanto ressocialização - uma espécie de institucionalização do "papel" ocupado pelo imigrante dentro dos limites da sociedade. Uma parte essencial desse processo seria a transformação dos grupos primários e sua participação na sociedade. Contudo, a depender tanto da abertura oferecida pela sociedade quanto da identificação do imigrante com os "papéis" sociais que Ihes são atribuídos, uma variedade de formas de organização se tornaria possível. Disso emergiriam estruturas pluralísticas.

Enfatizo aqui que, em um momento inicial, dois autores ligados a Florestan Fernandes produziram estudos sobre imigrantes e refletiram, em seus trabalhos, essas mudanças em curso. Em 1959, a antropóloga Ruth Cardoso publicou a sua dissertação de mestrado intitulada $O$ papel das associações juvenis na aculturação dos japoneses, sob orientação de Fernandes. É válido ressaltar que a questão geracional e da juventude compôs um dos eixos de investigação sociológica do Projeto de Tensões da UNESCO, a partir de um debate iniciado pelo sociólogo húngaro Karl Mannheim. Disso resultaram obras como Jeunesse sans chrysanthème ni sabre (1954), de Jean Stöetzel, e From generation to generation ([1956] 2003), de Shmuel Eisenstadt. Posteriormente, em sua tese de doutorado intitulada Estrutura familiar e mobilidade social - estudo dos japoneses no Estado de São Paulo (Cardoso, 1972), a autora fez da relação entre os processos de constituição étnica e a formação de classe a sua principal linha argumentativa: 
Sua posição na sociedade que o receber está dada dentro do sistema de classes. É, portanto, dentro da estrutura existente e em transformação que o imigrante procura mudar de posição e mede seu progresso [...] Sua dissolução como etnia significa sua absorção como membro de uma classe, o que constituiria sua integração total (Cardoso, 1994 [1972], p. 175-176).

Em 1961, Octávio lanni publicou um projeto de estudo sobre os imigrantes poloneses intitulado A situação social do polonês em Curitiba (lanni, 1961b), uma espécie de desdobramento dos achados de pesquisa anterior coordenada por Fernandes, em 1955, sobre relações étnico-raciais no Sul do Brasil ${ }^{\mathbf{2 9}}$. O autor escrevera o projeto após constatar o preconceito sofrido pelos poloneses, algo comparável ao caso do negro em outras regiões do país. O autor definiu como objetivo de análise o processo de integração desses imigrantes e, após apresentar uma ampla gama de definições do termo "integração" - inclusive fazendo referência a Willems e a autores da tradição assimilacionista de Chicago - , lanni diferenciou "integração" no sentido cultural do sentido social. No primeiro, a cultura do imigrante seria reinterpretada no novo contexto, enquanto, no segundo, o indivíduo, seus papéis sociais e padrões de comportamento seriam ressocializados no novo contexto.

Os trabalhos de Cardoso e lanni inauguraram outra vertente possível de interpretação sobre fenômenos que afetavam a vida de imigrantes para além do modelo cultural-assimilacionista, embora nunca tenham questionado a contribuição definitiva deste último para o desenvolvimento das ciências sociais no Brasil. Em especial, era bastante estabelecida a ideia de que Willems fora pioneiro, principalmente por introduzir técnicas de investigação profissionais (Duarte, 1955) e por ter sido exitoso em desvencilhar o debate sobre a presença estrangeira dos argumentos atrelados ao racialismo. Considerando-se o peso de fatores já elencados que possivelmente alimentaram disputas entre projetos acadêmicos distintos em São Paulo, a deflagração de mudanças em curso na organização disciplinar das ciências sociais brasileiras dependeu também de correspondências entre essas duas abordagens. É pouco provável que mudanças tenham ocorrido somente 29 Para mais detalhes, ver Oliveira, 2015. 
devido à falência intelectual de uma concepção de ensino e pesquisa, em geral atribuída ao declínio institucional da ELSP e à partida de seus pesquisadores estrangeiros, pois estes forneceram condições institucionais e alimentaram quadros teórico-metodológicos posteriores com conteúdos que foram absorvidos e ressignificados de maneira crítica.

Em meados dos anos cinquenta, Willems já havia deixado o país definitivamente. A condução dos estudos sobre assimilação nos moldes por ele apregoados coube ao sociólogo japonês Hiroshi Saito, formado na ELSP sob orientação de Donald Pierson. A despeito das mencionadas críticas dirigidas ao projeto acadêmico de seus mestres estrangeiros, Saito insistiu na utilização da abordagem cultural-assimilacionista em suas pesquisas, e ainda assim se inseriu no meio acadêmico paulista, sendo visto à época como um dos especialistas no tema da imigração. Boa parte de seus trabalhos foi dedicada ao estudo dos japoneses, muito embora também tenha feito pesquisas sobre os poloneses no Paraná, em 1955, assim como lanni, além de ter participado do Projeto de Tensões da UNESCO, em parceria com o antropólogo Seiichi Izumi (Taniguti; Jesus, 2012). Paralelamente, também participava das atividades da intelectualidade japonesa de São Paulo, porém nunca deixou de ser um estrangeiro em terras brasileiras, tendo sofrido um inquérito de expulsão do país (Taniguti, 2015).

Ademais, Saito esteve situado profissionalmente em um ambiente intelectual prolífico e ansioso pelo desenvolvimento de uma sociologia desapegada do etnocentrismo científico. Os esforços de cientistas sociais em especial o de Willems - em atestar a assimilação de grupos imigrados já haviam produzidos resultados efetivos, o que tornou a aplicação de seu modelo de análise algo progressivamente anacrônico. Pois, para certos grupos, como os japoneses, o discurso que passou a estabelecer a associação entre integração e mobilidade serviu como aporte cognitivo para as oportunidades de inclusão ofertadas no mercado. Contudo, isso não significou o desaparecimento de imaginários raciais e de estereótipos a eles imputados, mesmo até os dias atuais. O caso dos migrantes internos que passaram a se dirigir a São Paulo naquela mesma década é significativo sob 
esse ponto de vista. A sua presença crescente no tecido social encontrou fortes resistências na construção de ideologias regionais que afirmavam (e ainda afirmam) a existência de uma suposta excepcionalidade paulista ${ }^{30}$.

É importante ressaltar que, se certos grupos estigmatizados e subalternizados passaram progressivamente a valorizar as suas diferenças culturais em processos de construção de "identidades étnicas" de origem estrangeira, deve-se considerar, por um lado, que os esquemas analíticos formulados no âmbito científico foram produzidos em convergência, ou por vezes em parceria com lideranças intelectuais, a exemplo dos casos dos negros, japoneses e judeus. Por outro lado, esse conteúdo subsidiou discursos sobre a afirmação positiva de identidades em processos de formação racial ${ }^{31}$. Ou seja, o discurso integracionista foi adotado com relativo sucesso até mesmo por sujeitos que foram escolhidos como objeto de investigação em pesquisas sociológicas e antropológicas ${ }^{32}$. A partir dessa afirmação, avento que uma melhor compreensão da produção das ciências sociais sobre os imigrantes necessita ser situada em seu contexto de realização, em que se considerem fatores que extrapolem o conteúdo presente somente nas obras e atinem para os seus usos no universo das relações concretas.

\section{Considerações finais}

Recentemente, pesquisadores têm procurado interpretar a formação dos estudos sobre imigrantes nas ciências sociais brasileiras enfocando as obras de autores significativos. Neste artigo, afirmo que se trata de um debate que pode se beneficiar de um olhar ampliado sobre a produção do conhecimento científico, que não se restrinja ao conteúdo das obras, mas também sobre as condições que permitiram a sua realização. A transição de quadros de referência teórica e metodológica é um processo significativo, presente de maneira constitutiva na trajetória desses estudos, e por isso

30 Sobre esse assunto, ver Weinstein, 2015.

31 São exemplos os eventos: I Congresso do Negro Brasileiro (1950) e o I Painel NipoBrasileiro (1956).

32 A esse respeito, o simpósio O japonês em São Paulo e no Brasil, ocorrido em 1968, é um exemplo significativo. 
demanda exames detalhados. Os dados obtidos pela pesquisa empreendida indicam que a forma de conceber o imigrante nos modelos propugnados por cientistas sociais possui estreita relação com o desenvolvimento das ciências sociais brasileiras, em especial a sociologia.

Ao considerarmos eventos significativos na história dessa disciplina, os estudos sobre imigrantes realizados no âmbito da UNESCO possuem destaque. Eles foram capazes de apresentar novos dados empíricos sobre as formas de organização coletiva de grupos de diferentes origens em realidades nacionais e também contribuíram de maneira inédita para o desenvolvimento de novos referenciais teóricos e a formulação de políticas governamentais.

Os resultados apresentados indicam que principalmente Florestan Fernandes e alguns de seus colegas próximos foram responsáveis pela difusão de uma nova abordagem sobre a questão migratória em nível nacional a partir dos anos cinquenta. $\mathrm{O}$ autor tanto absorveu quanto elaborou novos entendimentos sobre a posição do imigrante, situando este em um esquema analítico interessado no desenvolvimento da ordem capitalista e na formação de classes sociais. Somado às críticas aos "estudos de comunidades", os estudos anteriormente voltados ao tema da mudança cultural foram reconfigurados sob a ótica desses autores, adequando-se ao novo contexto acadêmico-científico em curso.

Gustavo Takeshi Taniguti é pesquisador de pós-doutorado do Departamento de Sociologia da Universidade de São Paulo.

$\equiv$ gtaniguti@usp.br

\section{Referências}

1. ABRANTES, Antonio Carlos S. de. Ciência, educação e sociedade: o caso do Instituto Brasileiro de Educação, Ciência e Cultura (IBECC) e da Fundação Brasileira de Ensino de Ciências (FUNBEC). Tese de doutorado em história das ciências e da saúde. Rio de Janeiro: FIOCRUZ, 2008.

2. ANGELL, Robert Cooley. UNESCO and social science research. UNESCO/SS/ TAIU/19. UNESCO Archives, 1950. 
3. AVILA, Fernando B. de; DIÉGUES Jr., Manuel. A draft manual on the cultural integration of immigrants. UNESCO/SS/MIGRATION/Rev.1. Paris, 30 jan. 1959.

4. AZEVEDO, Thales de. Um questionário sobre estereótipos raciais. Sociologia, v. XIII, n. 1, p. 58-63, 1951.

5. BALDUS, Herbert, WILLEMS, Emílio. Casas e túmulos de japoneses no Vale do Ribeira de Iguape. Revista do Arquivo Municipal, v. VII, n. 77, p. 121-37, 1941.

6. BASTIDE, Roger; FERNANDES, Florestan. Relações raciais entre negros e brancos em São Paulo: ensaio sociológico as origens, as manifestações e os efeitos do preconceito de cor no município de São Paulo. São Paulo: Ed. Ánhembi, 1955.

7. BICUDO, Virgínia L. (1955). Atitudes dos alunos dos grupos de escolares em relação com a cor dos seus colegas. In: BASTIDE, Roger; FERNANDES, Florestan. Relações raciais entre negros e brancos em São Paulo: ensaio sociológico as origens, as manifestações e os efeitos do preconceito de cor no município de São Paulo. São Paulo: Ed. Anhembi, 1955, p. 227-310.

8. BLANCO, Alejandro; JACKSON, Luiz Carlos. Sociologia no espelho: ensaístas, cientistas sociais e críticos literários no Brasil e na Argentina (1930-1970). São Paulo: Editora 34, 2014.

9. BORRIE, Wilfred D.; DIÉGUES Jr., Manuel. The cultural integration of immigrants: a survey based upon the papers and proceedings of the UNESCO Conference held in Havana, April 1956. Paris: UNESCO, 1959.

10. BRASIL JR., Antonio. O imigrante e seus irmãos: as pesquisas empíricas de Florestan Fernandes e Gino Germani. Lua Nova, São Paulo, n. 81, p. 175-213, 2010.

11. CARDOSO, Ruth C. L. Estrutura familiar e mobilidade social: estudo dos japoneses no estado de São Paulo. São Paulo: Primus, [1972] 1995.

12. CASTRO E SILVA, Cecília; GUIMARÃES, Maria Stella. Pesquisa sobre a mancha pigmentária congênita na cidade de São Paulo. Revista do Arquivo Municipal, ano 3, v. XXXVI, p. 44-70, jun. 1937.

13. CASTRO, Peter A. Collaborative researchers or cold warriors? The origins, activities, and legacy of the Smithsonian's Institute of Social Anthropology. Journal of International and Global Studies, v. 2, n. 1, p. 56-82, 2010.

14. COSTA PINTO, Luiz de A. Sociologia e desenvolvimento. Rio de Janeiro: Civilização Brasileira, 1963.

15. CHRISTENSEN, Ivan L.; YDESEN, Christian. Routes of knowledge: toward a methodological framework for tracing the historical impact of international organizations. European Education, v. 47, n. 3, p. 274-88, 2015.

16. DUARTE, Paulo. Prefácio In: BASTIDE, Roger; FERNANDES, Florestan. Relações raciais entre negros e brancos em São Paulo: ensaio sociológico as origens, as manifestações e os efeitos do preconceito de cor no município de São Paulo. São Paulo: Ed. Anhembi, 1955. 
17. EISENSTADT, Shmuel. N. The absorption of immigrants. Londres: Routledge \& Kegan Paul, 1954.

18. EISENSTADT, Shmuel. N. From generation to generation. New Brunswick: Transaction Publ., [1956] 2003.

19. FARIA, Luis de C. Egon Schaden (1913-1991). Anuário antropológico, Rio de Janeiro, n. 91 p. 241-55, 1993.

20. FAULHABER, Priscila. O Instituto de Antropologia Social (EUA, Brasil e México): um artefato da resposta antropológica ao "esforço de guerra". Mana, Rio de Janeiro, v. 17, n. 1, p. 9-39, 2011.

21. FERNANDES, Florestan. A análise sociológica das classes sociais. Sociologia, v. 10, n. 2/3, p. 91-113, 1948.

22. FERNANDES, Florestan. A organização social dos Tupinambá. São Paulo: Progresso Editorial, 1949.

23. FERNANDES, Florestan. Considerações sobre a aplicação dos conhecimentos sociológicos às relações internacionais. Anais do I World Congress of Sociology. International Sociological Association. Zurique, Suíça, 4-9 setembro, 1950.

24. FERNANDES, Florestan. A aculturação dos sírios e libaneses em São Paulo. In: Florestan Fernandes: leituras e legados. São Paulo: Global, [1956] 2010, p. 226-34.

25. FERNANDES, Florestan. O negro no mundo dos brancos. São Paulo: Global Editora, [1965] 2007.

26. FERNANDES, Florestan. A revolução burguesa no Brasil: ensaio de interpretação sociológica. Rio de Janeiro: Zahar, 1975.

27. FERNANDES, Florestan. A integração do negro na sociedade de classes. São Paulo: Globo, [1978] 2008.

28. FRANCO, Maria Sylvia de C. O estudo sociológico de comunidades. Revista de Antropologia, São Paulo, v. 11, n. 1 e 2, p. 29-39, 1963.

29. GINSBERG, Aniela M. Um inquérito sobre as atitudes de estudantes baianos em relação a diversos grupos nacionais e raciais. Boletim de Psicologia, ano I, n. 4, p. 10-5, 1950.

30. GOLDWASSER, Maria Julia. Estudos de comunidade: teoria e/ou método? Revista de Ciências Sociais, Fortaleza, v. 5, n. 1, p. 69-81, 1974.

31. GOMES, Janaína D. Os segredos de Virgínia: estudo de atitudes raciais em São Paulo (1945-1955). Tese de doutorado em Antropologia Social - Faculdade de Filosofia, Letras e Ciências Humanas, Universidade de São Paulo, 2013.

32. GORDON, Milton M. Assimilation in American life. Nova York: Oxford University Press, 1964.

33. GUIMARÃES, Antonio Sérgio A. Baianos e paulistas: duas "escolas de relações raciais? Tempo Social, v. 11, n. 1, p. 75-95, 1999. 
34. GUIMARÃES, Antonio Sérgio A. Classes, raças e democracia. São Paulo: FUSP/Editora 34, 2002.

35. GUIMARÃES, Antonio Sérgio A. Como trabalhar com "raça" em sociologia. Educação e Pesquisa., São Paulo, v. 29, n. 1, p. 93-107, 2003.

36. GUIMARÃES, Antonio Sérgio A. Depois da democracia racial. Tempo Social, v. 18, n. 2., p. 269-287, 2006.

37. GUIMARÃES, Antonio Sérgio A. O projeto Unesco na Bahia. In: PEREIRA, Claudio.; SANSONE, Livio. (Org.). Projeto Unesco no Brasil. Salvador: EDUFBA, 2007, p. 25-37.

38. GUIMARÃES, Antonio Sérgio A. Comentários à correspondência entre Melville Herskovits e Arthur Ramos - 1835-1941. In: PEIXOTO, Fernanda A.; PONTES, Heloisa; SCHWARCZ, Lilia M. Antropologias, histórias, experiências. Belo Horizonte: Ed. da UFMG, 2008, p. 169-98.

39. GUIMARÃES, Antonio Sérgio A. Racismo e anti-racismo no Brasil. São Paulo: Editora 34, 2012.

40. HANDLIN, Oscar (Ed.). The positive contribution by immigrants: a symposium prepared for UNESCO by the International sociological Association and the International economic Association. Paris: UNESCO, 1955.

41. IANNI, Octávio. Estudo de comunidade e conhecimento científico. Revista de Antropologia, v. 9, n. 1/2, p. 109-19, 1961a.

42. IANNI, Octavio. A situação social do polonês em Curitiba. Sociologia, v. XXXIII, n. 4, p. 375-88, 1961 b.

43. IUSSP - INTERNATIONAL UNION FOR THE SCIENTIFIC STUDY OF POPULATION. Cultural assimilation of immigrants: papers presented under the auspices and published with the assistance of UNESCO on behalf of the Population Investigation Committee. Londres: Cambridge University Press, 1950.

44. JACKSON, Luis Carlos. Gerações pioneiras na sociologia paulista (1934-1969). Tempo Social, v. 19, n. 1, p. 115-30, 2007.

45. JACKSON, Luis Carlos. Divergências teóricas, divergências políticas: a crítica da USP aos 'estudos de comunidades'. Cadernos de Campo, n. 18, p. 273-80, 2009.

46. KISER, Clyde V. The 1949 Assembly of the International Union for the Scientific Study of Population. Population Index, v. 16, n. 1, p. 13-20, 1950.

47. KLINEBERG, Otto. The UNESCO project on international tensions. A challenge to the sciences of man. Discurso presidencial de Otto Klineberg por ocasião da assembleia anual da Associação Psicológica Oriental. International Social Science Bulletin, v. 1, n. 1-2. Paris: UNESCO, 1949.

48. KLINEBERG, Otto. Tensions affecting international understanding: a survey of research. Nova York: Social Science Research Council, 1950a. 
49. KLINEBERG, O. Comments on memorandum regarding research on race relations in Brazil. UNESCO Archives Box 323.1, $1950 \mathrm{~b}$.

50. LAQUA, Daniel. Transnational intellectual cooperation, the League of Nations, and the problem of order. Journal of Global History, v. 6, n. 2, p. 223-47, 2011.

51. LESSER, Alexander. Survey of research on Latin America by United States scientists and institutions. National Research Council (U.S.). Committee on Latin American Anthropology, 1946.

52. LOPES, Thiago da C.; MAIO, Marcos C. Comunidade e democracia na sociologia de T. Lynn Smith e José Arthur Rios. Revista Brasileira de Ciências Sociais, v. 32, n. 95, p. 1-21, 2017.

53. LOWRIE, Samuel H. Ascendência das crianças registradas nos parques infantis de São Paulo. Revista do Arquivo Municipal, v. XLI, nov. 1937.

54. LOWRIE, Samuel H. Imigração e crescimento da população no estado de São Paulo. São Paulo: Escola Livre de Sociologia e Política, 1938.

55. LYNN SMITH, Thomas. A sociologia da vida rural. Rio de Janeiro: Editora Casa do Estudante do Brasil, 1946.

56. MAIO, Marcos C. Uma polêmica esquecida: Costa Pinto, Guerreiro Ramos e o tema das relações raciais. Dados, Rio de Janeiro, v. 40, n. 1, 1997.

57. MAIO, Marcos C. Tempo controverso: Gilberto Freyre e o Projeto UNESCO. Tempo Social, v. 11, p. 111-36, 1999a.

58. MAIO, Marcos C. O projeto Unesco e a agenda das ciências sociais no Brasil dos anos 40 e 50. Revista Brasileira de Ciências Sociais, v. 14, n. 41, p. 141-58, $1999 b$.

59. MAIO, Marcos C. O racismo no microscópio: Oracy Nogueira e o projeto UNESCO. E.I.A.L., v. 19, n. 1, p. 36-51, 2008.

60. MAIO, Marcos C. Educação sanitária, estudos de atitudes raciais e psicanálise na trajetória de Virgínia Leone Bicudo. Cadernos Pagu, Campinas, n. 35, p. 30955, 2010.

61. MAIO, Marcos C.; OLIVEIRA, Nemuel da S.; LOPES, Thiago da C . Donald Pierson e o projeto do Vale do Rio São Francisco: cientistas sociais em ação na era do desenvolvimento. Dados, v. 56, p. 245-84, 2013.

62. MAIO, Marcos C.; SANTOS, Ricardo Ventura. Cientificismo e antirracismo no pós-2 ${ }^{-}$- Guerra Mundial: uma análise das primeiras declarações sobre raça da Unesco. In: MAIO, Marcos C.; SANTOS, Ricardo V. (Orgs.). Raça como questão: história, ciência e identidades no Brasil. Rio de Janeiro: Fiocruz, p. 145-70, 2010.

63. MARTUSCELLI, Carolina. Uma pesquisa sobre a aceitação de grupos nacionais, grupos 'raciais' e grupos regionais em São Paulo. Boletim de Psicologia, n. 3. São Paulo, p. 65-6, 1950. 
64. MAUGER, Gérard. Pour une sociologie de la sociologie. Notes pour une recherche. L'Homme et la société, n. 131, Politique des sciences sociales, p. 101-20, 1999.

65. MAUREL, Chloé. L'UNESCO de 1945 à 1974. Paris: Université PanthéonSorbonne - Paris I, 2006.

66. MICELI, Sérgio. Intelectuais à brasileira. São Paulo, Companhia das Letras, 2001.

67. MILLIET, Sérgio. A representação dos fenômenos demográficos. Revista do Arquivo Municipal, ano 4, v. XLIII, p. 213-18, jan. 1938.

68. MÖSSLINGER, Martina. Assimilation and integration discourses in the social sciences (1945-1962). Tese de Doutorado. Universität Wien, 2016.

69. MURPHY, Henry B. M. Personnes déplacées: recueil d'études sur la psychologie des réfugiés. Paris: Unesco/Fédération Mondiale pour la Santé Mentale, 1955.

70. OLIVEIRA, Isabela; DAMACENO, Janaína. 'Constituindo um campo': estudos de comunidade e o desenvolvimento das ciências sociais no Brasil (1940-1960). Cadernos de Campo, São Paulo, n. 18, p. 253-6, 2009.

71. OLIVEIRA, Márcio de. A inesperada descoberta de Otávio lanni sobre preconceito contra descendentes de imigrantes poloneses em Curitiba. Sociedade \& Estado, Brasília, v. 30, n. 3, p. 799-817, 2015.

72. OLIVEIRA, Nemuel da S.; MAIO, Marcos C. Estudos de comunidade e ciências sociais no Brasil. Sociedade \& Estado, v. 26, n. 3, p. 521-50, 2011.

73. OLIVEIRA VIANNA, Francisco José. Raça e assimilação. Rio de Janeiro: J. Olympio, [1932] 1959.

74. PEREIRA, Claudio; SANSONE, Livio. (Org.). Projeto Unesco no Brasil. Salvador: EDUFBA, 2007.

75. PEREIRA, João Baptista B. Os imigrantes na construção histórica da pluralidade étnica brasileira. Revista USP, São Paulo, n. 46, p. 6-29, 2000.

76. PETITJEAN, Patrick; DOMINGUES, Heloisa Maria B. A Unesco, o Instituto Internacional da Hileia Amazônica e a antropologia no final dos anos 40. In: FAULHABER, P.; TOLEDO, P. M. de (Orgs). Conhecimento e fronteira: história da ciência na Amazônia. Belém: Museu Paraense Emilio Goeldi, 2001, p. 83-109.

77. PIERSON, Donald. Survey of the literature on Brazil of sociological significance published up to 1940. Cambridge: Harvard University Press, 1945a.

78. PIERSON, Donald. O estudo de contato racial. Sociologia, v. 7, n. 1 e 2, p. 38-53, $1945 \mathrm{~b}$.

79. PIERSON, Donald. Exame crítico da ecologia humana. Sociologia, v. 10, n. 4, p. 227-41, 1948. 
80. PIERSON, Donald. Cruz das almas. Rio de Janeiro: Livraria José Olympio Editora, [1951] 1966.

81. PIERSON, Donald; VIEIRA da CUNHA, Mario W. Pesquisa e possibilidades de pesquisa no Brasil. (Com especial referência a "cultura" e "mudança cultural"). Parte I. Sociologia, v. 9, n. 3, p. 234-56, 1947a.

82. PIERSON, Donald; VIEIRA da CUNHA, Mario W. Pesquisa e possibilidades de pesquisa no Brasil. (Com especial referência a "cultura" e "mudança cultural"). Parte II. Sociologia, v. 9, n. 4, p. 350-78, 1947b.

83. PIERSON, Donald; VIEIRA da CUNHA, Mario W. Pesquisa e possibilidades de pesquisa no Brasil. (Com especial referência a "cultura" e "mudança cultural"). Parte III. Sociologia, v. 10, n. 1, p. 40-57, 1948.

84. RAMOS, Arthur. Os grandes problemas da antropologia brasileira. Sociologia, v. 10, n. 4, p. 213-26, 1948.

85. RANGIL, Teresa T. The politics of neutrality: UNESCO's Social Science Department, 1946-1956. CHOPE Working Paper n. 2011-08, 2011.

86. SEYFERTH, Giralda. A imigração no Brasil: comentários sobre a contribuição das ciências sociais. Revista Brasileira de Informação Bibliográfica em Ciências Sociais, n. 57, p. 7-47, 2004.

87. SOARES, Gláucio A. D. Sociedade e política no Brasil: desenvolvimento, classe e política durante a Segunda República. São Paulo: Difusão Européia do Livro, 1973.

88. SOLA, Lourdes. Idéias econômicas, decisões políticas. São Paulo: Edusp, 1998.

89. SOUZA, Rafael de Paula. Contribuição à etnologia paulista. Revista do Arquivo Municipal, v. XXXI, p. 95-105, 1937.

90. STÖETZEL, Jean. Jeunesse sans chrysanthème ni sabre. Étude sur les attitudes de la jeunesse japonaise d'après guerre. Paris: Plon-UNESCO, 1954.

91. STÖETZEL, Jean. Without the chrysanthemum and the sword: a study of the attitudes of youth in post-war Japan. Paris: UNESCO, 1955.

92. TANIGUTI, Gustavo T. Cotia, imigração, política e cultura. Tese de Doutorado em Sociologia, FFLCH/USP, São Paulo, 2015.

93. TANIGUTI, Gustavo T.; JESUS, Matheus G. Sociologie de l'immigrant: Hiroshi Saito et I'institutionalisation des études sur les Japonais du Brésil (1940-1960). Brésil(s), v. 2, p. 201-24, 2012.

94. TRUZZI, Osvaldo. Assimilação ressignificada: novas interpretações de um velho conceito. Dados, Rio de Janeiro, v. 55, n. 2, p. 517-53, 2012.

95. UNESCO. Report on social sciences organizations, existing in Brazil, which are willing to cooperate on resolutions 5.1.1.2, 5.1.1.3, and 5.1.1.4. of the Tensions Project. Paris: UNESCO Archive, 1948. 
96. UNESCO. Scope of studies on the cultural assimilation of immigrants. Meeting of Experts on Research Problems, UNESCO House, 3-5 jul, 1950. Unesco Archives (UNESCO/SS/TAIU/Conf.2/5). Paris, 30 jun. 1950a.

97. UNESCO. Comments and suggestions concerning the proposals for research on the cultural assimilation of immigrants. Meeting of experts on research problems, UNESCO House, 3-5 jul. 1950. UNESCO Archives (SS/TAIU/ Conf.2/2 (A)). Paris, 23 jun. 1950b.

98. UNESCO. The integration of migrants into the life of their countries of resettlement. Working paper. Conference on the cultural integration of immigrants. UNESCO/ SS/ Mig.Consf./5. Paris, Dezembro de 1955. Disponível em: < http://unesdoc.unesco.org/images/0015/001575/157561eb.pdf>

99. VALENTINI, Luisa. Um laboratório de antropologia: o encontro Mário de Andrade, Dina Dreyfus e Claude Lévi-Strauss (1935-1938). Dissertação de mestrado em antropologia social, Universidade de São Paulo, 2010.

100. VILLAS-BÔAS, Gláucia. De Berlim a Brusque, de São Paulo a Nashville. A sociologia de Emílio Willems entre fronteiras. Tempo Social, São Paulo, v. 12, n. 2, p. 171-88, 2000.

101. WAGLEY, Charles. Estudo de comunidades no Brasil sob perspectiva nacional. Revista Brasileira dos Municípios, ano VIII, n. 31, p. 189-99, 1955.

102. WEINSTEIN, Barbara. The color of modernity: São Paulo and the making of race and nation in Brazil. Durham: Duke University Press, 2015.

103. WILCOX, C. Robert Redfield and the development of American anthropology. Lanham, MD: Lexington Books, 2006.

104. WILLEMS, Emílio. Assimilação e populações marginais no Brasil: estudo sociológico dos imigrantes germânicos e seus descendentes. São Paulo: Companhia Editora Nacional, 1940.

105. WILLEMS, Emílio. Procesos de culturalización lingüística entre poblaciones brasileñas de origen germánico. Revista Mexicana de Sociología, v. 3, n. 1, p. 35-45, 1941a.

106. WILLEMS, Emílio. Recreação e assimilação entre imigrantes alemães e japoneses e seus descendentes. Sociologia, v. 3, n. 4, p. 302-10, 1941 b.

107. WILLEMS, Emílio. Cultural change among Japanese immigrants in Brazil in the Ribeira Valley of São Paulo. Sociology and Social Research, v. 26, n. 6, p. 525-37, 1942a.

108. WILLEMS, Emílio. Some aspects of cultural conflict and acculturation in southern rural Brazil. Rural Sociology, v. 7, n. 4, p. 375-84, 1942b.

109. WILLEMS, Emílio. A solução do problema rural brasileiro como mudança social provocada. Sociologia, v. 5, n. 1, p. 20-8, 1943.

110. WILLEMS, Emílio. O problema rural brasileiro do ponto de vista antropológico. Tempo Social, v. 21, n. 1, p. 187-210, [1944] 2009. 
111. WILLEMS, Emílio. A aculturação dos alemães no Brasil: estudo antropológico dos imigrantes alemães e seus descendentes no Brasil. São Paulo: Ed. Nacional, 1946a.

112. WILLEMS, Emílio. A sociologia da vida rural [Resenha]. Sociologia, v. 8, n. 4, p. 317-18, $1946 b$.

113. WILLEMS, Emílio. Cunha: tradição e mudança em uma cultura rural do Brasil. São Paulo: Secretaria da Agricultura do Estado de São Paulo, 1947.

114. WILLEMS, Emílio; MUSSOLINI, Gioconda. Buzios Island: a caiçara community in southern Brazil. Anais da American Ethnological Society, XX. Locust Valley: J. J. Augustin Publisher, 1952. 